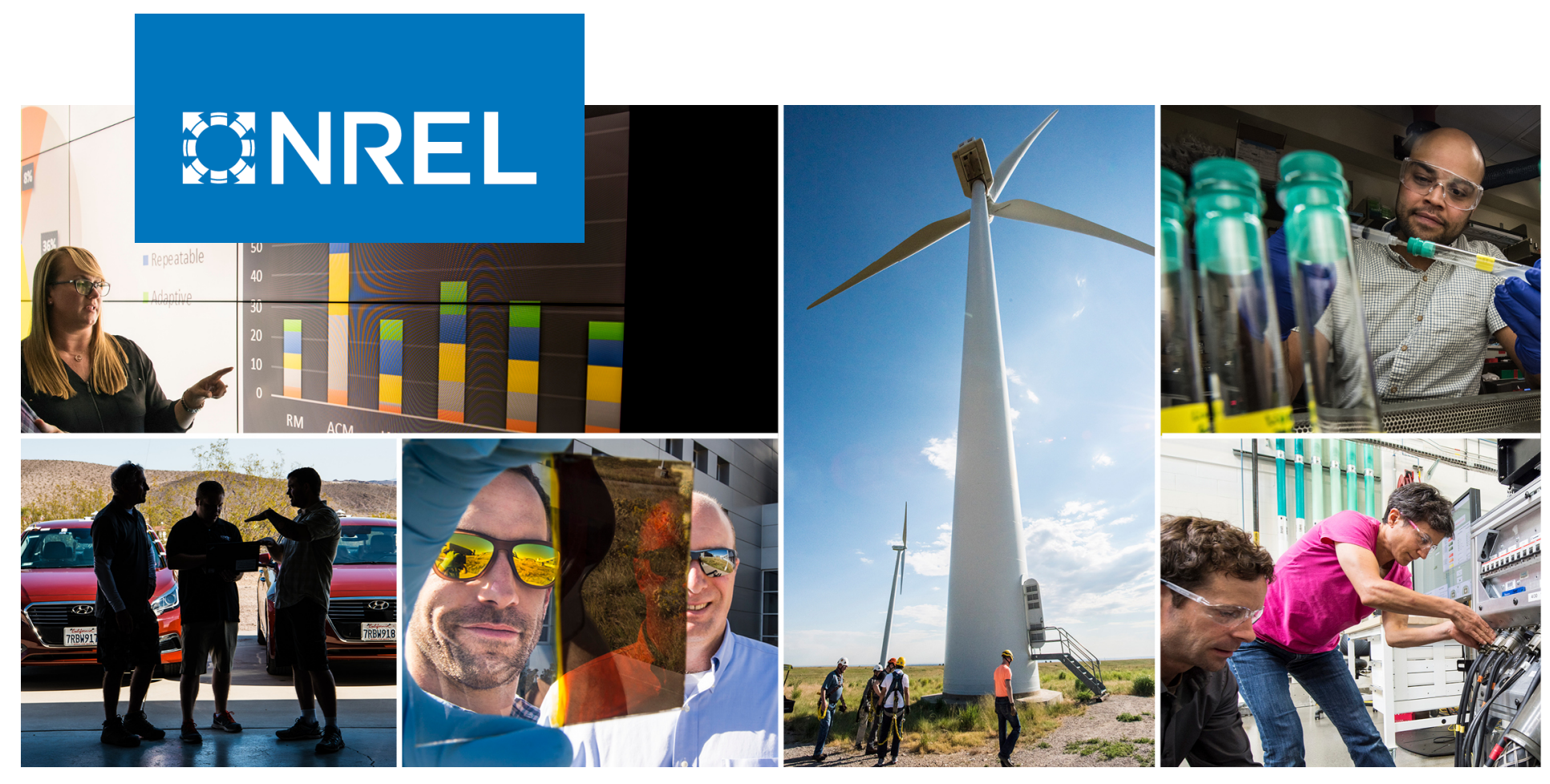

\title{
An Overview of the Waste-to-Energy System Simulation (WESyS) Model
}

Annika Eberle, ${ }^{1}$ Irina Tsiryapkina, ${ }^{1}$ Steve Peterson, ${ }^{2}$ Laura Vimmerstedt, ${ }^{1}$ Dylan Hettinger, ${ }^{1}$ and Daniel Inman ${ }^{1}$

1 National Renewable Energy Laboratory

2 Lexidyne, LLC

NREL is a national laboratory of the U.S. Department of Energy Office of Energy Efficiency \& Renewable Energy

Operated by the Alliance for Sustainable Energy, LLC

This report is available at no cost from the National Renewable Energy Laboratory (NREL) at www.nrel.gov/publications.
Technical Report

NREL/TP-6A20-77166

October 2020 


\title{
GNREL
}

\section{An Overview of the Waste-to-Energy System Simulation (WESyS) Model}

\author{
Annika Eberle, ${ }^{1}$ Irina Tsiryapkina, ${ }^{1}$ Steve Peterson, ${ }^{2}$ \\ Laura Vimmerstedt, ${ }^{1}$ Dylan Hettinger, ${ }^{1}$ and Daniel Inman ${ }^{1}$
}

1 National Renewable Energy Laboratory

2 Lexidyne, LLC

\section{Suggested Citation}

Eberle, Annika, Irina Tsiryapkina, Steve Peterson, Laura Vimmerstedt, Dylan Hettinger, and Daniel Inman. 2020. An Overview of the Waste-to-Energy System Simulation (WESyS) Model. Golden, CO: National Renewable Energy Laboratory. NREL/TP-6A20-77166. https://www.nrel.gov/docs/fy21osti/77166.pdf.

NREL is a national laboratory of the U.S. Department of Energy Office of Energy Efficiency \& Renewable Energy Operated by the Alliance for Sustainable Energy, LLC

This report is available at no cost from the National Renewable Energy Laboratory (NREL) at www.nrel.gov/publications.

Contract No. DE-AC36-08GO28308
Technical Report NREL/TP-6A20-77166 October 2020

National Renewable Energy Laboratory 15013 Denver West Parkway Golden, CO 80401 303-275-3000 • www.nrel.gov 


\section{NOTICE}

This work was authored in part by the National Renewable Energy Laboratory, operated by Alliance for Sustainable Energy, LLC, for the U.S. Department of Energy (DOE) under Contract No. DE-AC36-08GO28308. Funding provided by U.S. Department of Energy Office of Energy Efficiency and Renewable Energy Bioenergy Technologies Office. The views expressed herein do not necessarily represent the views of the DOE or the U.S. Government.

This report is available at no cost from the National Renewable Energy Laboratory (NREL) at www.nrel.gov/publications.

U.S. Department of Energy (DOE) reports produced after 1991 and a growing number of pre-1991 documents are available free via www.OSTI.gov.

Cover Photos by Dennis Schroeder: (clockwise, left to right) NREL 51934, NREL 45897, NREL 42160, NREL 45891, NREL 48097, NREL 46526.

NREL prints on paper that contains recycled content. 


\section{Acknowledgments}

This work was supported by the U.S. Department of Energy under Contract No. DE-AC3608GO28308 with Alliance for Sustainable Energy, LLC, the Manager and Operator of the National Renewable Energy Laboratory. Funding was provided by the U.S. Department of Energy Office of Energy Efficiency and Renewable Energy, Bioenergy Technologies Office. We thank representatives of several organizations, including Pacific Northwest National Laboratory, Waste Management, Inc., California Air Resources Board, Mainstream Engineering, The Water Research Foundation, HDR Inc., and Brown and Caldwell, for providing helpful comments and suggestions about the model. We also thank Liz Craig, Brian Bush, Corey Peck, Jake Jacobson, Amy Schwab, and Mike Meshek for their review and refinement of this report and the supporting figures. The views and opinions of the authors expressed herein do not necessarily state or reflect those of the United States Government or any agency thereof. Neither the United States Government nor any agency thereof, nor any of their employees, makes any warranty, expressed or implied, or assumes any legal liability or responsibility for the accuracy, completeness, or usefulness of any information, apparatus, product, or process disclosed, or represents that its use would not infringe upon privately owned rights. 


\section{List of Acronyms and Abbreviations}

Btu

CA

CAFO

$\mathrm{CF}$

$\mathrm{CH} 4$

CHP

$\mathrm{CNG}$

DOC

DOE

EPA

FCI

GJ

HTL

LCFS

LF

LMOP

MAX

MFSP

MGD

MJ

MSW

NoWTE

NPV

NREL

Op Cost

$\mathrm{PC}$

PNG

POTW

PR

PTC

REC

RFS

RGS

RIN

RNG

ROTUS

SB 1383

USD

WESyS

WTE
British thermal units

California

concentrated animal feeding operation

capture and flare

methane

combined heat and power

compressed natural gas

degradable organic content

U.S. Department of Energy

U.S. Environmental Protection Agency

fixed capital investment

gigajoule

hydrothermal liquefaction

Low Carbon Fuel Standard (California)

landfill

Landfill Methane Outreach Program

maximum

minimum fuel selling price

million gallons per day

megajoule

municipal solid waste

no waste-to-energy

net present value

National Renewable Energy Laboratory

operating costs

precommercial

pipeline natural gas

publicly owned treatment works

progress ratio

production tax credit

renewable energy certificate

renewable fuel standard

renewable gas standard

renewable identification number

renewable natural gas

rest of the United States

Senate Bill No. 1383 (California)

U.S. dollars

Waste-to-Energy System Simulation

waste-to-energy 


\section{Executive Summary}

The leveraging of waste streams for energy and chemical production could add revenue to waste disposal operations, and it presents opportunities for addressing a variety of economic and environmental objectives at the local, state, and national levels. The Waste-to-Energy System Simulation (WESyS) model is a system dynamics model that was created to simulate the development of the U.S. waste-to-energy industry over time. For each of the three primary waste resources modeled (landfills, concentrated animal feeding operations, and publicly owned treatment works), WESyS simulates technically feasible scenarios for use of the waste, including direct conversion to fuels, and anaerobic digestion followed by flaring, electricity generation, combined heat and power, cleanup and compression to compressed natural gas, and cleanup and injection into an existing pipeline. The model allows users to explore numerous plausible future scenarios for the development of the U.S. waste-to-energy industry. This report provides an overview of the WESyS model and documents the key assumptions, equations, and data sources used to create the model. 


\section{Table of Contents}

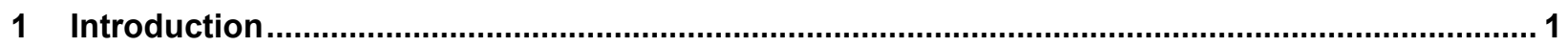

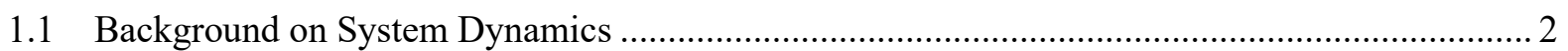

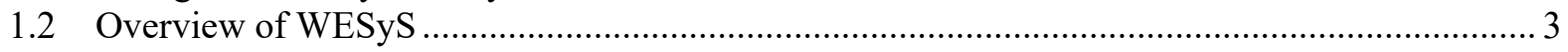

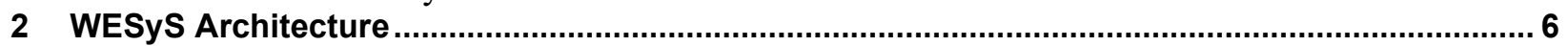

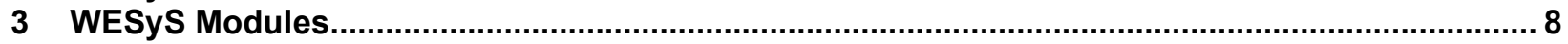

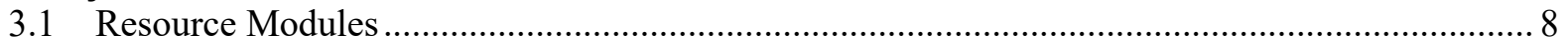

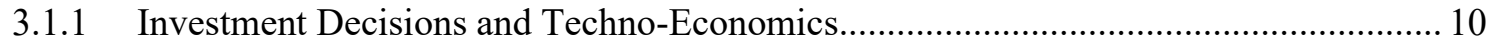

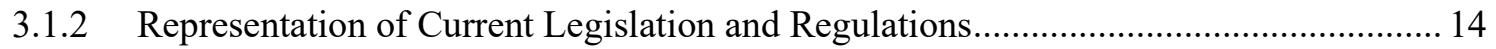

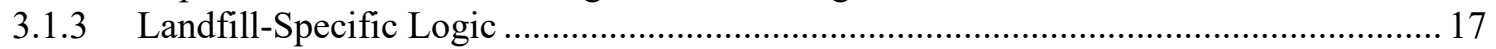

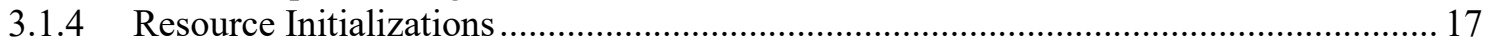

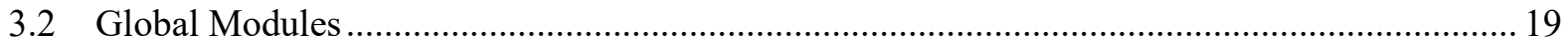

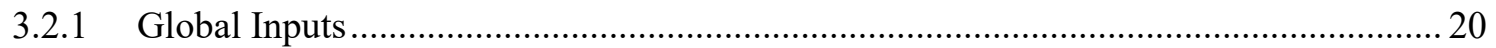

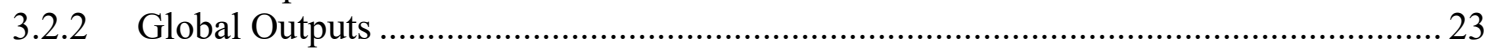

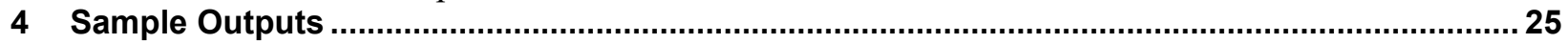

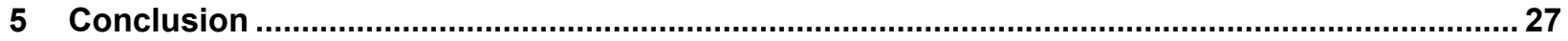

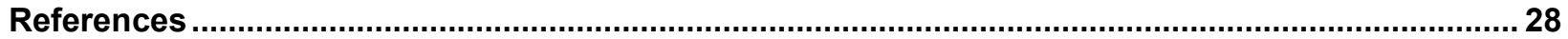

Appendix. Default Cost Data 


\section{List of Figures}

Figure 1. Simplified diagram showing stocks, a flow, and feedback loop ............................................ 2

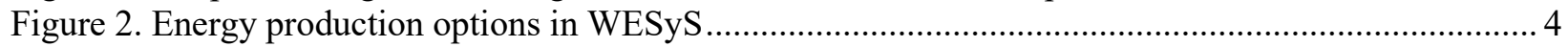

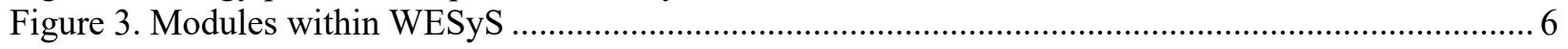

Figure 4. Investment decision process in WESyS ...................................................................... 7

Figure 5. Generalized structure used within a resource module .......................................................... 9

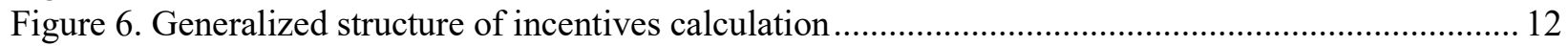

Figure 7. Generic representation of relative attractiveness calculations ........................................... 13

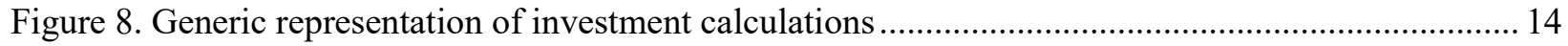

Figure 9. Generic representation of WTE investment levels ............................................................. 14

Figure 10. Generic structure for Low Carbon Fuel Standard (LCFS) calculations ................................. 16

Figure 11. Generic structure for estimating methane production from landfills..................................... 17

Figure 12. Diagram of per-unit revenue calculations in Global Inputs Module ...................................... 20

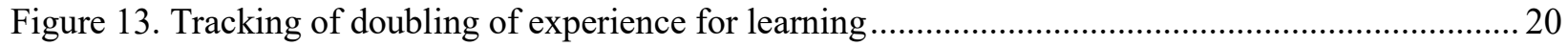

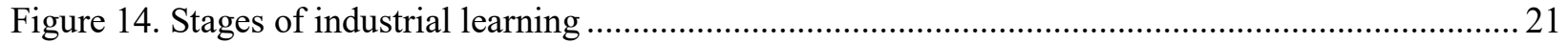

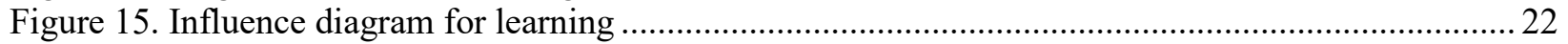

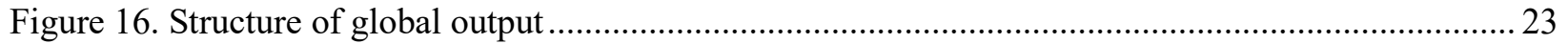

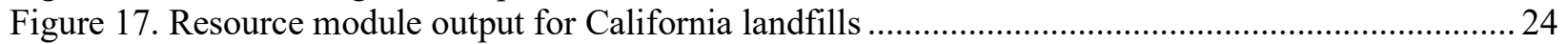

Figure 18. Sample energy production trajectories from the CA and ROTUS POTW modules..................2 25

Figure 19. Sample time series WESyS output for total energy production by resource type .....................26

Figure 20. Sample breakdown of WESyS ROTUS POTW facility counts by WTE technology ............... 26

\section{List of Tables}

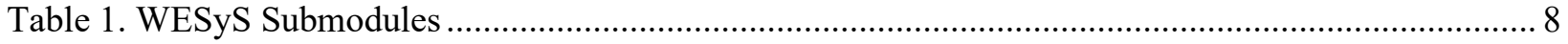

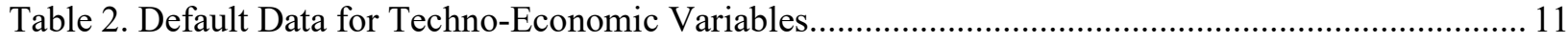

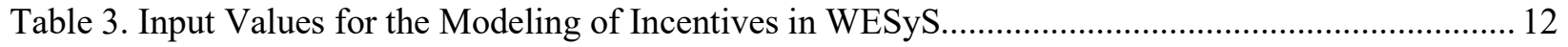

Table 4. Default Data for Current Legislative and Regulatory Variables............................................... 15

Table 5. Summary of Initialization Data for POTWs in California (CA) and the Rest of the United States (ROTUS)

Table 6. Summary of Initialization Data for the Number of Facilities and Average Amount of Waste in the CAFO Resource Modules ${ }^{\mathrm{a}}$ by Region ${ }^{\mathrm{b}}$....................................................................... 18

Table 7. Summary of Initialization Data used for the Number of Facilities in Each Landfill in the

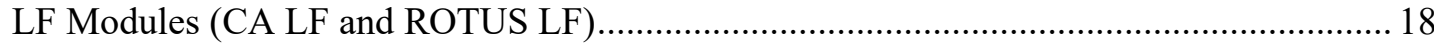

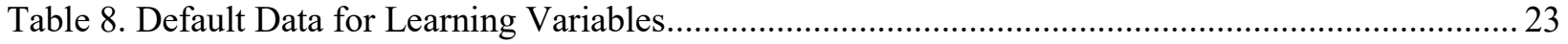




\section{Introduction}

The total annual energy potential of wet and gaseous waste resources in the United States, including wastewater residuals, animal waste, biogas, and black liquor, is estimated to be more than 2.3 quadrillion British thermal units (Btu) (DOE 2017). This much energy is equivalent to $\sim 8 \%$ of the energy used by the U.S. transportation sector in 2018 (EIA 2018). Increasing the share of U.S. energy generated from waste resources presents opportunities for achieving a variety of local, regional, and national objectives, including increasing energy security. Accordingly, the federal government is investing across a wide variety of new and established waste-to-energy (WTE) technologies to promote their commercialization (DOE n.d.). However, market transformations and the adoption of nascent technologies, including those found in the WTE industry, are markedly uncertain and risky. New technologies, in particular, often struggle to progress further than demonstration projects and fail to achieve commercial scale. To overcome these barriers, decision makers need to understand system bottlenecks and identify opportunities to support the transformation to a more established industry.

The Waste-to-Energy System Simulation (WESyS) model uses a system dynamics modeling framework (Sterman 2000) to provide a simulation-based approach for developing a better understanding of how political, industrial, and technological components of the WTE industry might impact market transformation. This approach allows researchers and decision makers to explore industrial and consumer behaviors in the context of historical, current, and possible future conditions. We chose a system dynamics approach because it can aid understanding of the potential development and expansion of new and evolving industries by:

1. Providing a tool set for representing key physical and decision processes associated with industry evolution

2. Serving as a vehicle for incorporating multiple perspectives, data, and assumptions in a visual framework

3. Facilitating a process of hypothesis development, testing, and insight generation, even though much may not yet be known about the industry.

WESyS is designed to analyze the development of the emerging WTE industry in the United States, with a specific focus on energy production potential from landfills (LFs), publicly owned treatment works (POTWs), and concentrated animal feeding operations (CAFOs). ${ }^{1}$ The model explicitly represents the behavior of decision makers such as facility operators and investors. It allows users to perform scenario analyses to (1) better understand how individual parts of the supply chain, as well as the industry as a whole, function and (2) how this system interacts and responds to a range of incentives, techno-economics, and market conditions. WESyS represents selected laws, rules, and regulations through incentives, financing options, and landfill diversion quantities. By characterizing responses to these conditions in the decision-making behaviors of economic actors within the supply chain, users can explore variation in the adoption rate of new WTE technologies.

\footnotetext{
${ }^{1}$ See Section 3.1.4 for details about resource types and initialization data.
} 


\subsection{Background on System Dynamics}

System dynamics has been used in a wide range of contexts to represent and simulate dynamic systems that are driven by multiple interacting physical and social components. WESyS uses a system dynamics approach to encode a system of coupled ordinary differential equations, integrating these equations forward in time. WESyS thus captures interdependencies among rates of change of key parameters, and feedbacks between variables representing physical, technical, economic, and behavioral aspects of the WTE supply chain. A system dynamics model has two essential elements: ${ }^{2}$

1. Stocks and Flows: Accumulations (stocks), and the activities (flows) that cause accumulations to rise and fall over time, are fundamental to the generation of dynamics. System dynamics models are built up from stock and flow components. In WESyS, we use stocks primarily to track the state of WTE resources in terms of the number, type, and size of conversion installations on each type of waste processing facility. Corresponding flows capture the changes over time in the status of each facility that result from investment decisions.

2. Feedback: Dynamic social systems can contain rich webs of feedback processes. Positive feedbacks tend to drive accelerating change - either growth or decline - in key quantities, and negative feedbacks underwrite self-correcting behavior. In WESyS, we seek to capture key feedbacks within and across each stage of the WTE supply chain, and we draw on resiliency thinking (Walker and Salt 2012) in the design of the modular architecture of the model.

These elements are illustrated in Figure 1.

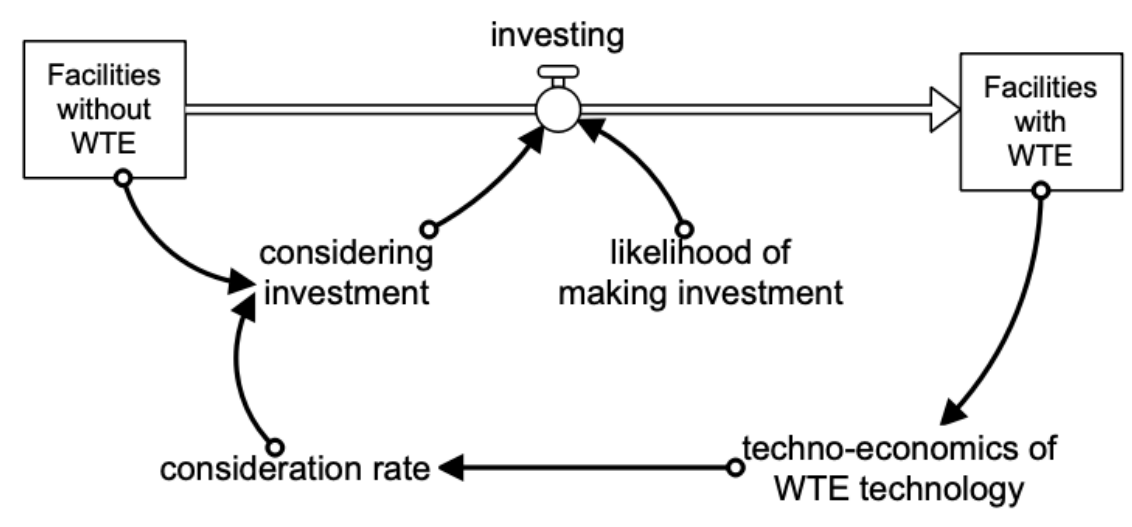

Figure 1. Simplified diagram showing stocks, a flow, and feedback loop

Stocks (rectangles) represent accumulations. In this illustration, stocks are used to represent the WTE adoption status of facilities (i.e., with or without WTE). Flows represent the activities that change the magnitude of stocks over time. In this illustration, a single flow (directed "pipe" called investing) is used to represent the investment activity that moves facilities from "without WTE" to "with WTE" status. Directed arrows represent logical or causal connections between model variables (e.g., consideration rate). In this illustration, the connections from "Facilities with WTE" to "techno-economics of WTE technology" to "consideration rate" and "considering investment" to "investing" create a feedback loop.

\footnotetext{
${ }^{2}$ See Sterman (2000) for details.
} 


\subsection{Overview of WESyS}

WESyS is a high-level, dynamic model developed to provide insights regarding the possible evolution of the WTE industry in the coming decades. It is not intended to be a precise forecasting tool or point prediction model, but it is generally adept at producing results that encapsulate a variety of potential outcomes given a set model structure and a variety of input assumptions. The model is built in a commercial system dynamics simulation tool called Stella Architect. ${ }^{3}$ The model is solved numerically at a submonthly level and typically reports output for 2015-2040. It is important to recognize that insights from the model are subject to the limitations of input data, model structure, and scenario design. Accordingly, analysis with WESyS often consists of insight development, followed by careful identification of conditions under which the insight is likely to hold true.

WESyS models WTE technology adoption for three types of waste resources: CAFOs, POTWs, and LFs (Figure 2, next page). Depending on the resource type, the model allows for seven types of investment options, five of which use anerobic digestion (or direct biogas generation in landfills):

- Capture and flare (CF)

- Combined heat and power (CHP)

- Electricity

- Compressed natural gas (CNG)

- Pipeline-injected renewable natural gas (PNG). ${ }^{4}$

The other two WTE technology options represented in WESyS do not use anaerobic digestion: no WTE and biofuel produced via hydrothermal liquefaction (HTL). ${ }^{5}$ For technologies that are not commercially mature, the model represents two production scales: precommercial and fullscale commercial.

\footnotetext{
${ }^{3}$ WESyS is publicly available on GitHub at https://github.com/NREL/WESyS-Model. It requires Stella Architect to run (more information about this software, including potential trial downloads, can be found at https://www.iseesystems.com/store/products/stella-architect.aspx). Refer to the GitHub repository for details about how to run the model.

${ }^{4}$ See DOE (2017) for details about each of these WTE technologies.

${ }^{5}$ See Snowden-Swan et al. (2017) for details about HTL.
} 


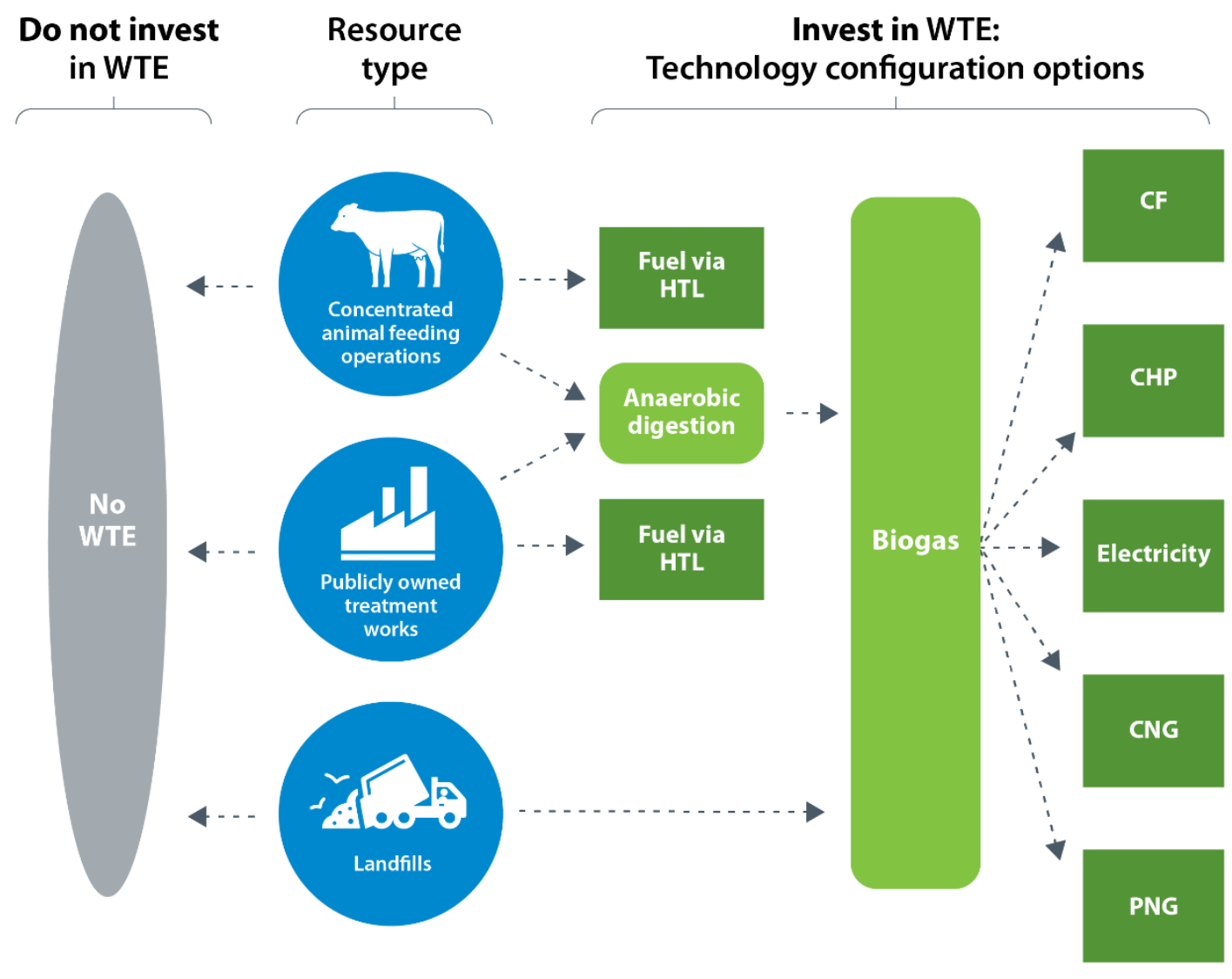

Figure 2. Energy production options in WESyS

WESyS evaluates the potential energy available from three types of waste resources: concentrated animal feeding operations, publicly owned treatment works, and landfills (shown in blue circles). Depending on the resource type, the facility may choose from seven investment options: six options include investing in WTE technology (dark green boxes on right) or one option not to invest in WTE technology (NoWTE: gray box on the left).

WESyS was designed in a top-down, modular fashion, which allows material (resources) to flow down the supply chain and to be converted into various types of energy, with feedback mechanisms interacting between the various modules. Systems of equations (both algebraic and integro-differential) both within the sectors and across sectors and modules specify the relationships between variables such as prices, costs, facilities, resources, and material. In some cases, the equations represent physical or economic constraints or relationships, whereas others embody behavioral models such as investor decision-making and consumer choices. In general, WESyS endogenizes the determination of revenue, production, investment, and demand, and it relies on exogenously specified scenarios such as energy prices for boundary conditions.

The WESyS model structure is transparent, modular, and extensible, enabling stand-alone analysis of individual modules as well as testing of different module combinations. It is geographically stratified into two regions: California (CA) and the rest of the United States (ROTUS). Modules exist for each region and resource combination as well as for global inputs and outputs. Each module reflects decisions on facility construction and operation based on the net present value (NPV) of the potential cost/benefit of investing or operating each type of WTE 
technology configuration. Modules receive and respond to information about industrial learning, project economics, installed infrastructure, and simulated initiatives.

WESyS is particularly adept at addressing the following types of research questions:

- Which waste resources might plausibly contribute to energy production in different regions of the United States, and how much energy potential do they have?

- Under what combination of incentives might the WTE industry experience gradual, sustained growth?

- How might different fuel price scenarios impact the build-out of the WTE industry?

Answering these types of questions allows users to gain a view into the potential evolution of the WTE industry and understand how the trajectory of development might change as incentives, technology yields and costs, and other conditions vary. 


\section{WESyS Architecture}

We designed WESyS using a modular approach to represent each combination of waste resource (LF, POTW, and CAFO) and region (CA and ROTUS). Using a modular architecture (Figure 3) facilitates model changes such as adding additional regions or waste resources.

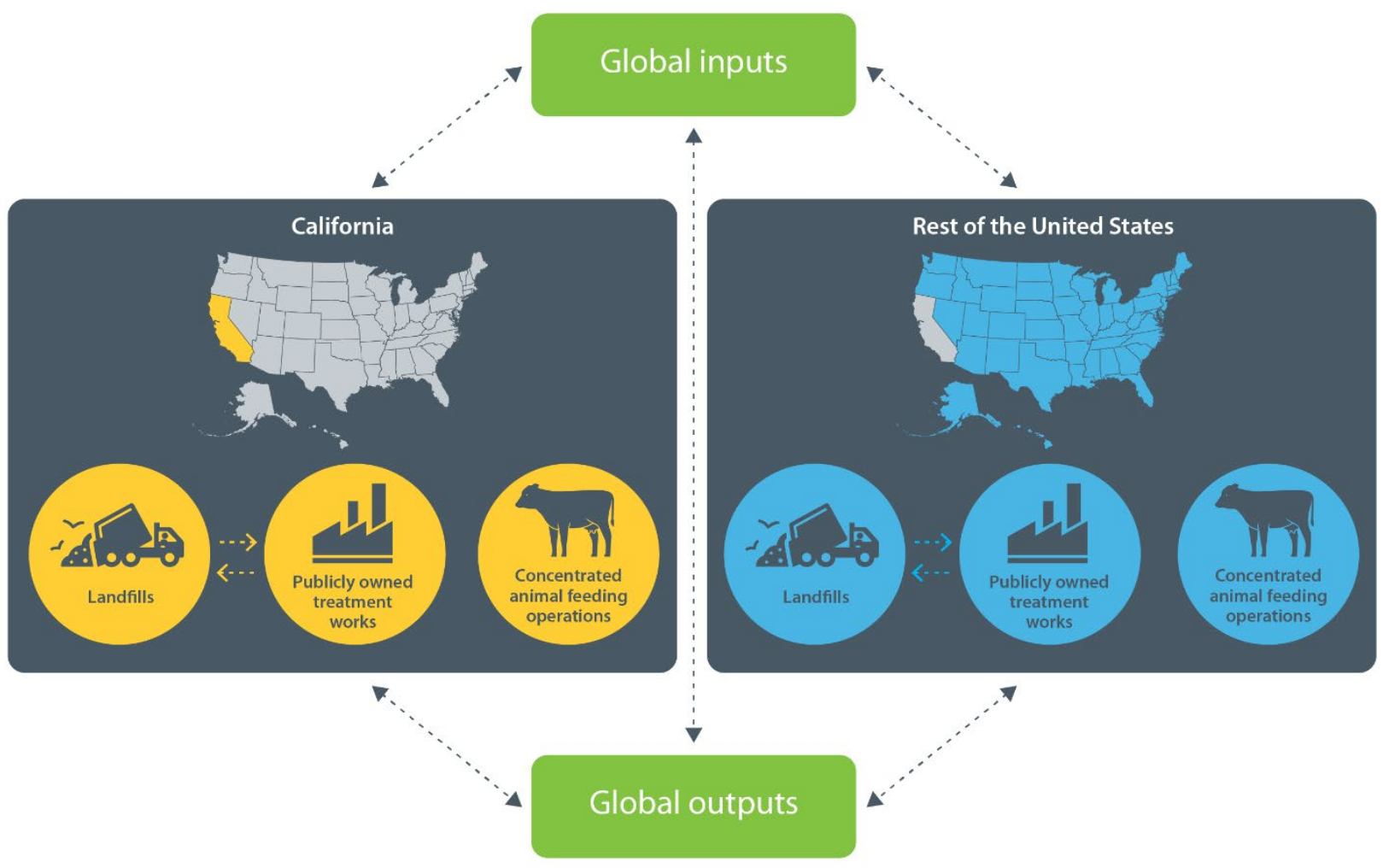

Figure 3. Modules within WESyS

The arrows shown represent the connections between modules within WESyS. Connections include the exchange of data or information (e.g., learning curve information is tracked in the inputs module and passed back and forth between the regions and resource types).

Figure 4 illustrates the essence of the investment decision process that is modeled in WESyS. As shown, techno-economic inputs and expected per-unit facility production are combined with other factors, including incentives, production credits, and other environmental incentives. All this information is used to calculate the NPV of each type of incremental investment decision that could be made by a facility. The financial attractiveness of each investment is then compared across multiple technologies, at small, medium, and large investment scales. And this comparison informs which investment option (including not investing in any WTE technology) is most attractive. 
Techno-economic inputs

Process yields

Technology costs

Expected per-unit production

By resource type At multiple scales

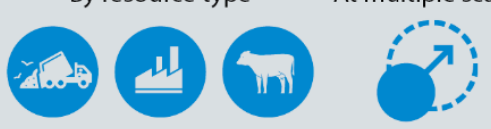

Current legislation and regulations
Production
By region
credits

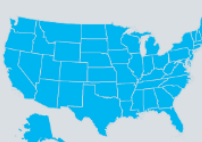
Incentives
ther environmenta
incentives

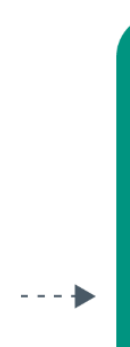

of incremental

investment

for each WTE

technology

option at each

scale

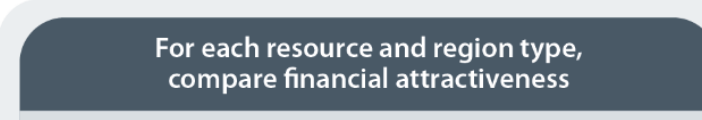

compare financial attracti

Multiple WTE At multiple Including a "do

technologies scales nothing" option

Invest in

proportion

to the

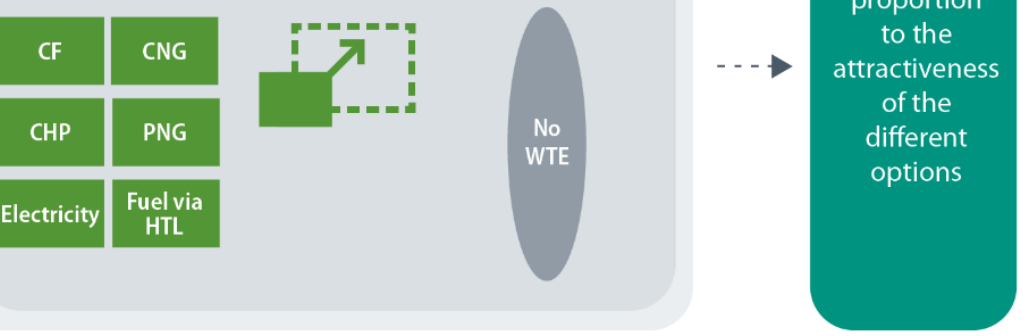

\section{Figure 4. Investment decision process in WESyS}

WESyS incorporates techno-economic inputs, expected per-unit production, and current legislative and regulatory conditions to calculate the NPV of the incremental investment for each type of WTE technology option shown in Figure 2. For each resource type and region, the model compares the financial attractiveness of each option and invests in proportion to the attractiveness of each of the options.

PTC = production tax credit; RECs = renewable energy credits; RINs = renewable identification numbers; SB 1383 = California Senate Bill No. 1383. 


\section{WESyS Modules}

WESyS is composed of eight main modules: six resource modules define resource dynamics (LF, CAFO, and POTW for both CA and ROTUS) and two (Global Inputs and Global Outputs) manage the input and output data (Figure 3). The Global Inputs Module also models learning dynamics for technologies that are not yet commercially mature; at the time of this report, fuel via HTL was the only immature technology modeled in WESyS.

\subsection{Resource Modules}

Within each resource module, the model performs calculations to estimate facility production for each type of resource and expected revenue for each technology configuration, and it then calculates the NPV of each potential WTE technology configuration that could be adopted (Figure 5, next page). The NPV is used to estimate the relative attractiveness of each investment, which informs the investment decision process and thereby estimates which technologies are adopted by different types and sizes of facilities. In the LF modules, additional calculations are performed to determine how much biogas a landfill can produce over time and how many landfills close in each time step of the simulation. These calculations are supported by five submodules (Table 1), which are detailed in the remainder of this section and in Section 3.2.

Table 1. WESyS Submodules

Submodules are represented using "sectors" in the Stella Architect software.

\begin{tabular}{|l|l|}
\hline Submodule Name & Documentation Section \\
\hline $\begin{array}{l}\text { NPV and Invest Submodule } \\
\text { Incentives Submodule }\end{array}$ & 3.1.1 Investment Decisions and Techno-Economics \\
\hline LCFS Submodule & 3.1.2 Representation of Legislation and Regulations \\
\hline LF Biogas Submodule & 3.1.3 Landfill-Specific Logic \\
\hline Learning Submodule & 3.2.1 Global Inputs \\
\hline
\end{tabular}

a LCFS = Low Carbon Fuel Standard. Although LCFSs are in effect or being considered in multiple U.S. states (e.g., Oregon Department of Environmental Quality 2015), WESyS only implements an LCFS in the California region (based on the California LCFS; CARB 2020). 
NPV and Invest Submodule

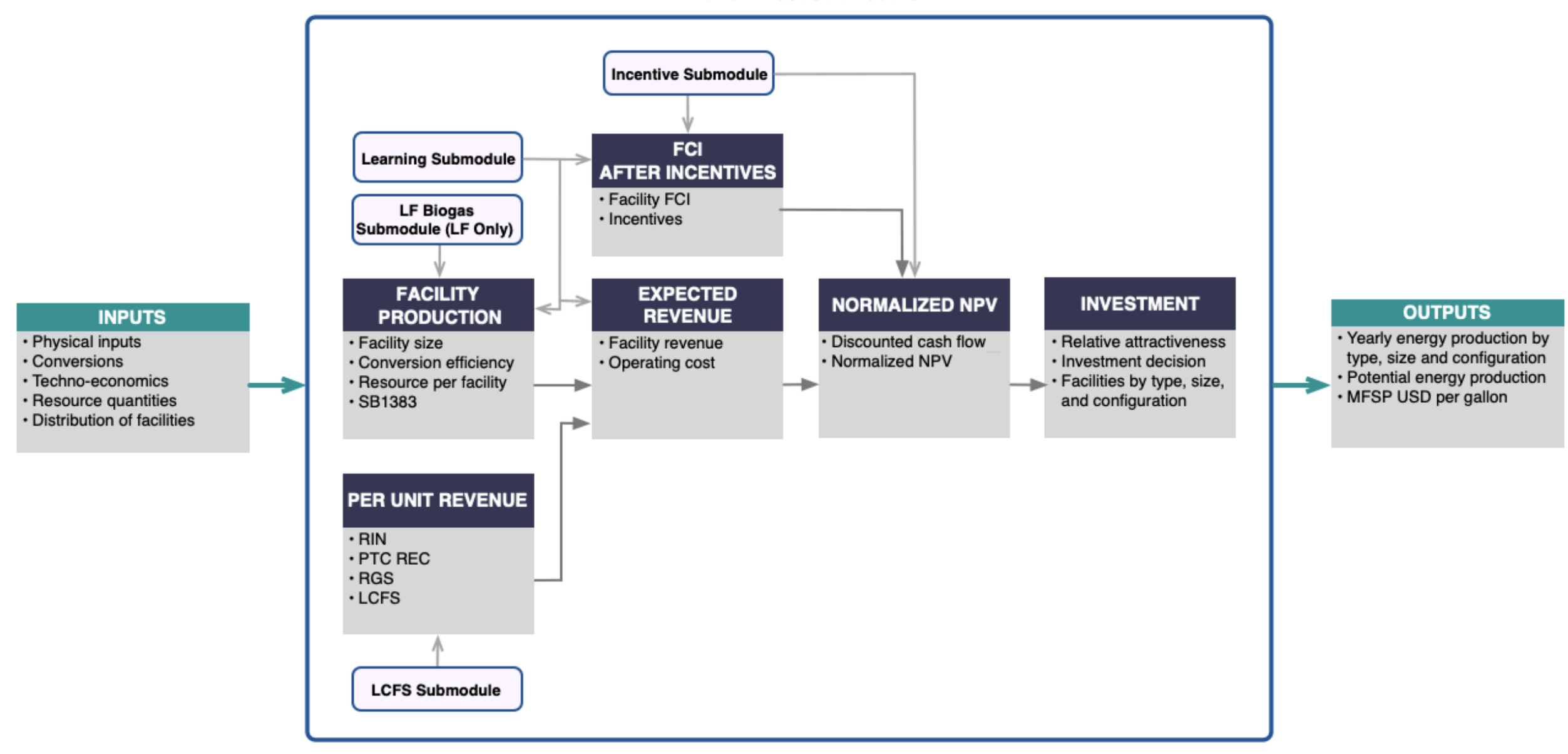

Figure 5. Generalized structure used within a resource module

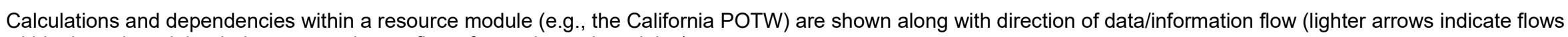
within the submodule; darker arrows denote flows from other submodules).

$\mathrm{FCl}$ = fixed capital investment; MFSP = minimum fuel selling price; RGS = renewable gas standard; USD = US dollar.

Refer to figures in the remainder of the text for details about the four other submodules: Incentive Submodule (Figure 6), Learning Submodule (Figures 13 and 14), LCFS Submodule (Figure 10), and LF Biogas Submodule (Figure 11). 


\subsubsection{Investment Decisions and Techno-Economics}

The concept of choice is fundamental to the adoption of WTE conversion infrastructure in WESyS. At any point in simulated time, facilities can choose to invest in one of multiple conversion options, at multiple scales, or they can decide to forego investment (illustrated in Figure 4). Investment choices change the state of the system and consequently will change available investment options over time. The model uses logit functions to allocate investment among these multiple mutually exclusive conversion options.

Applied originally in the context of consumer choice, a logit choice formulation expresses the likelihood $\mathbf{P}$ of choosing alternative $\mathbf{i}$ from the set of $\mathbf{j}$ alternatives given an observed utility of $\mathbf{x}$; for details, see Lilien, Kotler, and Moorthy (1992). In the context of WESyS, this probabilistic interpretation is applied to a population of actors within each class of unique resources (e.g., large active landfills that currently have only capture and flare installation-see Section 3.1.4 for details about resource categorizations). WESyS computes the NPV of each alternative investment available to each class of actors. This NPV metric serves as the utility component of the logit formulation. Investment decisions over time thus reflect a set of economic choices.

To inform the investment decision process, WESyS computes the NPV of each WTE configuration option based on the difference between the potential revenues and costs of each pathway. To scale the costs for each size of investment (e.g., a facility choosing to invest at $25 \%$ of its full capacity), WESyS applies the rule of sixth-tenths to user inputs for the fixed capital investment (FCI) and operating costs (Op Cost) (Humphreys 1991). The equation for this scaling of costs is given by:

$$
C_{2}=C_{1}\left(\frac{S_{2}}{S_{1}}\right)^{S F}
$$

where $C_{2}$ is the approximate cost of the equipment in U.S. dollars (USD) for the new size, $S_{2}$, $C_{1}$ is the known cost of the equipment (in U.S. dollars) for size, $S_{1}$, and $S F$ is the scaling factor (default of 0.6). The default FCI and Op Cost data for WESyS are based on publicly available data on WTE technologies (Snowden-Swan et al. 2017; Murray, Galik, and Vegh 2017); see Tables A-1 through A-4 in the appendix.

The NPV and Invest Submodule (primary structure shown in Figure 5) calculates a normalized NPV of each potential investment, including capital costs, revenues ${ }^{6}$, operating costs, loans, and taxes. As shown in Figure 5, the NPV and Invest Submodule draws on inputs from the other five submodules and performs calculations to estimate discount factors and determine relative attractiveness. Within each resource module, facilities are categorized either as being an adopter (of energy conversion equipment at different scales) or a nonadopter, based on expected net relative per-operation revenues. The techno-economics of converting waste to energy varies

\footnotetext{
${ }^{6}$ The default value for revenue from coproduct (e.g., fertilizer) sales in WESyS is set to zero (Table 2). However, it is important to note that coproduct revenues could play an important role in the profitability of WTE operations, particularly at CAFOs. Other potential benefits of installing an anaerobic digester at a CAFO include reducing odors and runoff of phosphates and nitrates from raw manure applications, which WESyS does not incorporate. WESyS users can adjust the price of any coproduct to reflect their specific use case.
} 
considerably depending on the type of facility, the size of the facility, the type of conversion system being used, and the scale of the potential investment relative to the size of the facility (default data for techno-economic values are listed in Table 2). The NPV Submodule calculates a normalized NPV of each potential investment, including capital costs, revenues, operating costs, loans, and taxes. To achieve this, the NPV Submodule draws on inputs from the Incentive Submodule and computes the discounted cash flow for each technology configuration.

Table 2. Default Data for Techno-Economic Variables

\begin{tabular}{|c|c|c|}
\hline Model Factor & Default Data & Units \\
\hline Depreciation Period & 20 & years \\
\hline Solids Energy Density Wastewater & 16.13 & million Btu/ton \\
\hline Solids Energy Density Manure & 10.2 & million Btu/ton \\
\hline Energy Content Ethanol & 77,500 & Btu/gallon \\
\hline Development Dwell Time ${ }^{a}$ & 6 & years \\
\hline Add-On Dwell Timea & 3 & years \\
\hline Dwell Time Multiplier ${ }^{a}$ & 1 & unitless \\
\hline Plant Economic Lifetime & 20 & years \\
\hline $\begin{array}{l}\mathrm{FCl} \text { and Operating Cost Scaling Factors } \\
(\mathrm{SF} \text { in Equation } 1)\end{array}$ & 0.6 & unitless \\
\hline Coproduct Sale Revenue & 0 & USD/year \\
\hline Pipeline Length & 1 & miles \\
\hline Expected Equity Fraction & 0.2 & unitless \\
\hline Expected Tax Rate & 0.4 & unitless \\
\hline Required Rate of Return & 8 & percentage \\
\hline Digester Biogas Yield & 283 & $\mathrm{~m}^{3} /$ million gal \\
\hline PNG Pipeline Cost & 200 & USD/ft \\
\hline Energy Prices (e.g., electricity and fuel) & Time series & USD/unit \\
\hline Tipping Fee & 52.21 & USD/tonne \\
\hline Fertilizer Revenue & 26 & USD/ton \\
\hline $\begin{array}{l}\text { Fraction of Solids Remaining } \\
\text { after Processing }\end{array}$ & $\begin{array}{l}\text { 0.14: HTL } \\
\text { 0.50: Electricity, CNG, PNG, CHP } \\
\text { 1.00: NoWTE, CF }\end{array}$ & unitless \\
\hline
\end{tabular}

Sources: EIA 2018; Snowden-Swan et al. 2017; Galik, and Vegh 2017; Roos, Martin, and Moser 2004.

${ }^{a}$ Dwell time represents how much time it takes for WTE technology to be installed after a project is initiated (e.g., the time required for permitting, financing, and construction of the new technology). In WESyS, Development Dwell Time is the dwell time that is required for facilities that do not have any capture and flare technology installed; AddOn Dwell Time is for facilities that do have capture and flare technology and are installing anerobic digestion pathways. The Dwell Time Multiplier is a user input that allows for fractional changes in these dwell times $(1=$ default value and $0.5=50 \%$ of default value).

$\mathrm{CF}=$ capture and flare; NoWTE = no WTE technology. 
The Incentive Submodule (Figure 6) calculates FCI subsidies, loan guarantees, and pipeline interconnection incentives as either a fraction of the full cost or as an amount of money in U.S. dollars. The incentive calculation relies on several inputs, which are listed in Table 3.

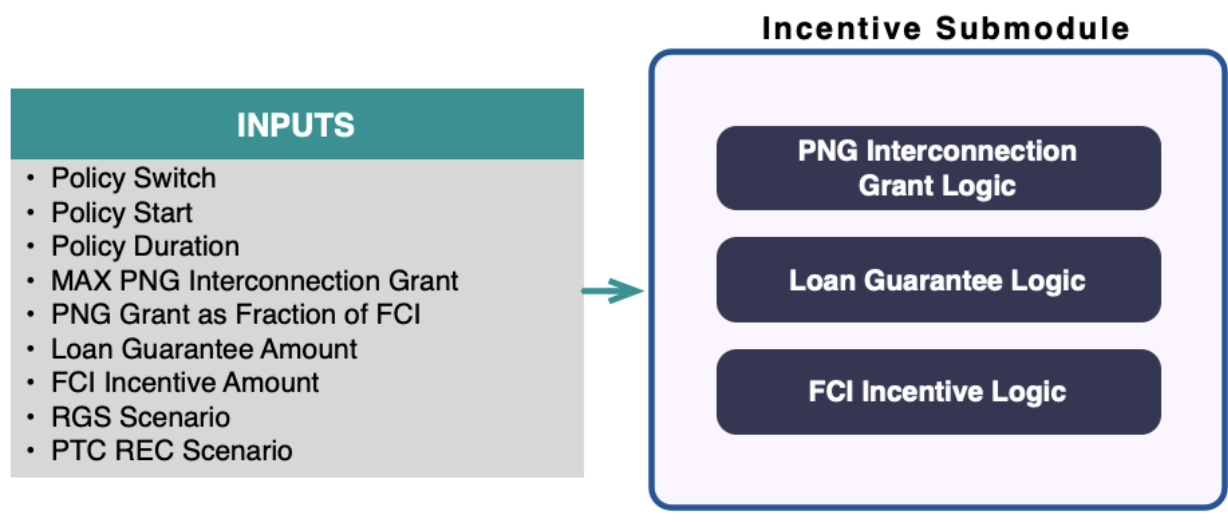

Figure 6. Generalized structure of incentives calculation

The Incentive Submodule uses several inputs (left; default values in Table 3 ) to estimate the incentives a project might qualify for, including PNG interconnection grants, loan guarantees, and $\mathrm{FCl}$ incentives. The module also tallies credits from an RGS and a PTC REC.

Table 3. Input Values for the Modeling of Incentives in WESyS

\begin{tabular}{|c|c|c|c|}
\hline Model Factor & \multicolumn{2}{|l|}{ Default Data } & Units \\
\hline $\begin{array}{l}\text { Policy Switch (turns the incentive } \\
\text { pathway on or off in the model) }\end{array}$ & \multicolumn{2}{|c|}{ Varies by pathway and region } & unitless \\
\hline Policy Start & $\begin{array}{l}\mathrm{FCl}: \\
\text { Loan: } \\
\text { PNG Connect }\end{array}$ & $\begin{array}{l}2010 \\
2010 \\
2015\end{array}$ & years \\
\hline Policy Duration & $\begin{array}{l}\mathrm{FCl}: \\
\text { Loan: } \\
\text { PNG Connect }\end{array}$ & $\begin{array}{l}0 \text { or } 30 \\
0 \\
6\end{array}$ & years \\
\hline MAX PNG Interconnection Grant & $\begin{array}{l}\text { CAFO: } \\
\text { LF: } \\
\text { POTW: }\end{array}$ & $\begin{array}{l}5,000,000 \\
3,000,000 \\
3,000,000\end{array}$ & USD \\
\hline $\begin{array}{l}\text { PNG Interconnection Grant as } \\
\text { Fraction of FCl }\end{array}$ & 0.5 & & unitless \\
\hline Loan Guarantee Amount & 0 & & fraction (unitless) \\
\hline $\mathrm{FCl}$ Incentive Amount & $0-0.5$ & & unitless \\
\hline RGS Scenario Input & Time series & & USD/gallon \\
\hline PTC REC Scenario Input & Time series & & USD/REC \\
\hline
\end{tabular}


The NPV and Invest Submodule (Figure 5) takes in outputs from the Incentive Submodule and performs a discounted cash flow analysis to calculate the NPV of expected costs and revenues for each investment option. The NPV and Invest Submodule computes five different discount factors that are applied to five different types of costs and revenues:

1. Loan repayment

2. Design, construction, and startup

3. Portion of project lifetime up to end of depreciation period or end of loan term, whichever comes first (Period 1)

4. Portion of project lifetime up to end of depreciation period or end of loan term, whichever comes last (Period 2)

5. Discount factor for total commercial project length.

The NPV of each investment is normalized by the amount of energy that could be produced (Figure 7). The normalized NPV then gets converted to a relative attractiveness factor, which is a normalized NPV-informed value that estimates how attractive each WTE investment option is compared to the other options (including no investment).

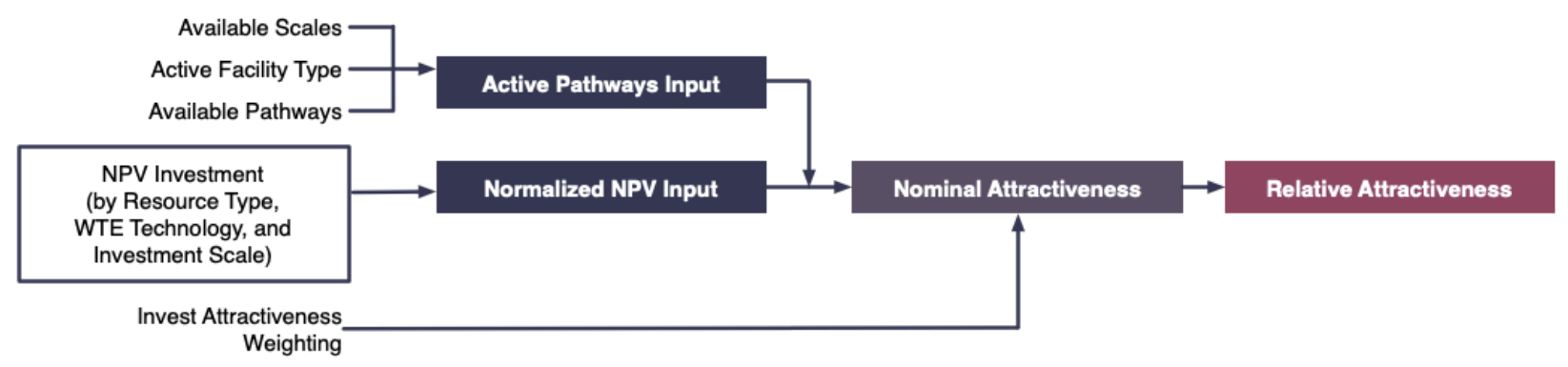

Figure 7. Generic representation of relative attractiveness calculations

The relative financial attractiveness of each WTE technology option is computed by normalizing the NPV of each investment and estimating the nominal attractiveness of each technology option. These calculations are made for each resource type, WTE technology, and investment scale.

The investment decision process uses the relative attractiveness factor to inform an investment "batchifier" calculation ${ }^{7}$ that translates a continuous signal (e.g., the attractiveness of investment in a particular conversion option) into a discrete decision about whether to invest (Figure 8). The batchifier represents the investment process in WTE technology configuration when a variety of investment options at multiple scales are possible, and it estimates how many facilities invest in WTE technology (as compared to no investment).

\footnotetext{
${ }^{7}$ In WESyS, a "batch" is a single facility.
} 


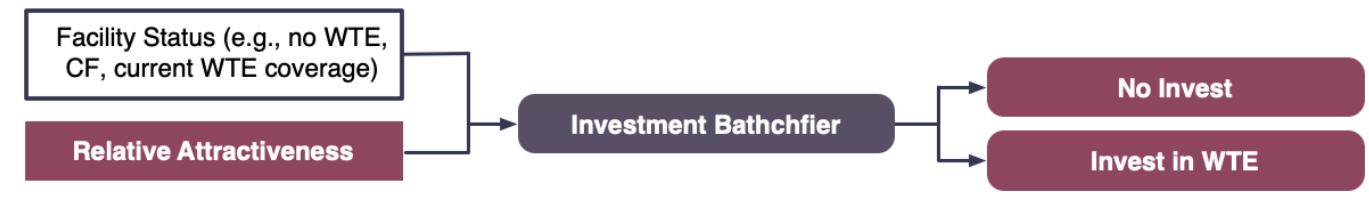

Figure 8. Generic representation of investment calculations

The relative attractiveness of each investment option (computed as shown in Figure 7) is combined with the status of the facilities (e.g., no WTE) to inform the investment batchifier, which translates the attractiveness of a particular WTE technology option into a discrete decision to invest (or not) in a new WTE technology pathway.

These investment decisions are developed for different scales of investment at each type of facility (i.e., a facility can choose to invest in WTE technology configurations that utilizes $100 \%$ of its waste resource or it can choose to invest at lower levels). As the result of an investment decision, a facility can land in one of the six different states (Figure 9). The arrows in Figure 9 show how investment decisions change the state of the system.

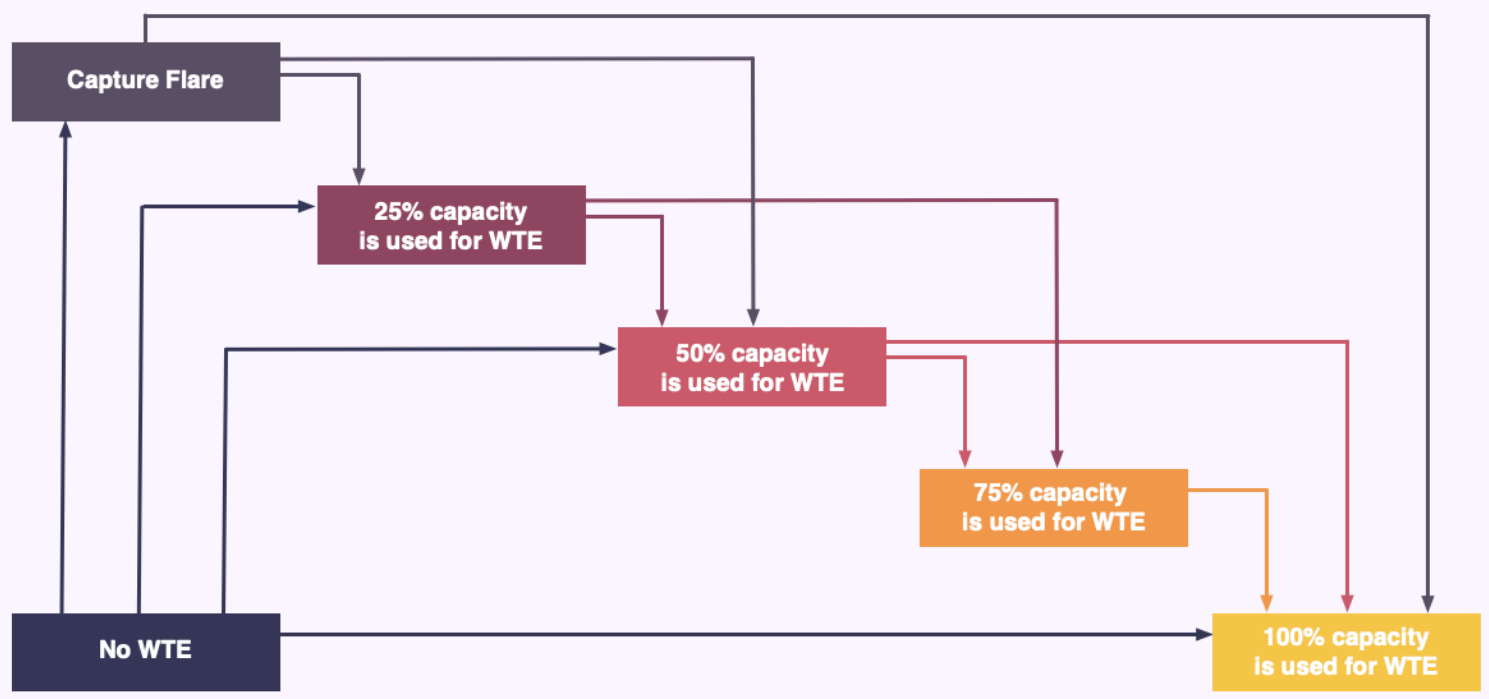

Figure 9. Generic representation of WTE investment levels

The arrows show how investment decisions change the state of the system (e.g., from NoWTE a facility can invest in CF, $25 \%$ capacity for WTE, $50 \%$ capacity for WTE, or $100 \%$ capacity for WTE).

\subsubsection{Representation of Current Legislation and Regulations}

As described in Section 3.1.1, the Incentive Submodule represents a few generic incentive-based conditions, such as FCI incentives, interconnection grants for pipeline natural gas, and renewable gas standards. In addition, WESyS represents selected national and California-only laws, rules, and regulations, totaling four major factors that influence WTE decision-making:

1. Landfill diversion requirements (specifically SB 1383$)^{8}$

${ }^{8}$ California State Legislature (2016) 
2. The ability to rate-base development of WTE facilities at POTWs ${ }^{9}$

3. The renewable fuel standard (RFS) ${ }^{10}$

4. The California Low Carbon Fuel Standard (LCFS) ${ }^{11}$

The representations of these factors are described briefly in Sections 3.1.2.1-3.1.2.3, and the default data are listed in Table 4.

Table 4. Default Data for Current Legislative and Regulatory Variables

\begin{tabular}{|c|c|c|c|}
\hline Category & Model Factor & Default Data & Units \\
\hline \multirow[t]{2}{*}{$\begin{array}{l}\text { California Senate Bill } \\
1383 \text { (SB 1383) }\end{array}$} & $\begin{array}{l}\text { SB } 1383 \text { Influx } \\
\text { Multiplier }\end{array}$ & $\begin{array}{l}1 \text { in California } \\
0 \text { in ROTUS }\end{array}$ & unitless \\
\hline & $\begin{array}{l}\text { Fraction Organics from } \\
\text { SB } 1383 \text { go to POTW }\end{array}$ & 0.95 & unitless \\
\hline \multirow[t]{2}{*}{$\begin{array}{l}\text { Rate-Base Development } \\
\text { at POTWs }\end{array}$} & $\begin{array}{l}\text { Allowed Rate of } \\
\text { Return }\end{array}$ & 0.05 & 1/year \\
\hline & Use Rate Base Input & $\begin{array}{l}\text { Electricity }=1 \\
\text { Other technologies }=0\end{array}$ & unitless \\
\hline \multirow{2}{*}{$\begin{array}{l}\text { Renewable Fuel } \\
\text { Standard (RFS) }\end{array}$} & RIN Scenario Input & Time series & USD/D3 RIN \\
\hline & $\begin{array}{l}\text { Renewable Content } \\
\text { Ethanol }\end{array}$ & 0.931 & unitless \\
\hline \multirow[t]{3}{*}{$\begin{array}{l}\text { Low Carbon Fuel } \\
\text { Standard (LCFS) }\end{array}$} & $\begin{array}{l}\text { Carbon Intensity } \\
\text { by Technology }\end{array}$ & $\begin{array}{l}\text { CAFO } \\
\text { CNG }=-260 \\
\text { Other Tech }=0 \\
\text { LF } \\
\text { CNG }=35.67 \\
\text { Other Tech }=0 \\
\text { POTW } \\
\text { CNG }=30.75 \\
\text { Other Tech }=0\end{array}$ & grams/megajoule \\
\hline & $\begin{array}{l}\text { Energy Density LCFS } \\
\text { Std. }\end{array}$ & $\begin{array}{l}\text { Gasoline: } 119.53 \\
\text { Diesel: } 134.47\end{array}$ & megajoule/gallon \\
\hline & LCFS Credit & Time series & USD/tonne \\
\hline
\end{tabular}

Sources: California State Legislature (2016) for SB 1383; CPUC (2018) for rate-base development at POTWs; EPA (2015) for RFS; and CARB (2020) for LCFS.

ROTUS (i.e., except California); D3 RIN = cellulosic biofuel RIN; Std. = standard.

${ }^{9}$ CPUC (2018)

${ }^{10}$ EPA (2015)

${ }^{11}$ CARB (2020) 


\subsubsection{SB 1383}

To represent landfill diversion in California in WESyS, we examine SB 1383, which sets a timeline for the diversion of organic wastes from landfills. The landfill diversion requirement is only applied to the CA LF Module and the CA POTW Module. To represent this legislation, WESyS performs a set of calculations that reduce the amount of organic waste (in tons per year) based on the SB 1383 time frame $(50 \%$ by 2020 , and $75 \%$ by 2025$)$ as compared to the total amount of waste and organics that went to California landfills in 2014. WESyS includes a parameter that determines how much of this diverted waste goes from landfills to POTWs.

\subsubsection{Rate-Base Development at POTWs}

In some cases, POTWs can take advantage of rate-of-return regulation to recover the cost of capital associated with developing WTE facilities (i.e., POTWs can recover costs by increasing the rates they charge for water treatment). The rate of return that a POTW may receive on the cost of capital is determined by regulators, and it includes the cost of debt and the cost of equity. If the rate-basing option is enabled, WESyS sets the expected equity fraction to zero because we assume the facility could finance everything with debt (i.e., public bonds) and we modify the required rate of return to equal the debt interest rate, which we set to $3 \%$, as this is a reasonable approximate rate in today's municipal bond market. Under rate-based financing, decision makers tend to select the most expensive option or options. For example, the California Public Utilities Commission (CPUC 2018) has published recommendations to limit rate-base increases to finance only projects that directly tie into a state goal (e.g., LCFS or SB 1383). Accordingly, in WESyS, the rate-based option is only available to CA POTWs investing in electricity generation.

\subsubsection{Renewable Fuel Standard (RFS) and Low Carbon Fuel Standard (LCFS)}

For the RFS and the LCFS, WESyS incorporates biofuel production incentives and assumes the incentive is accrued at the point of production. For the RFS, these incentives are incorporated by accepting time-series data that represent the production incentives from the renewable identification number (RIN) market. For the LCFS, the model's LCFS Submodule (Figure 10) mimics the low-carbon fuel standard credit calculations in U.S. dollars per gigajoule (USD/GJ) of produced fuel.

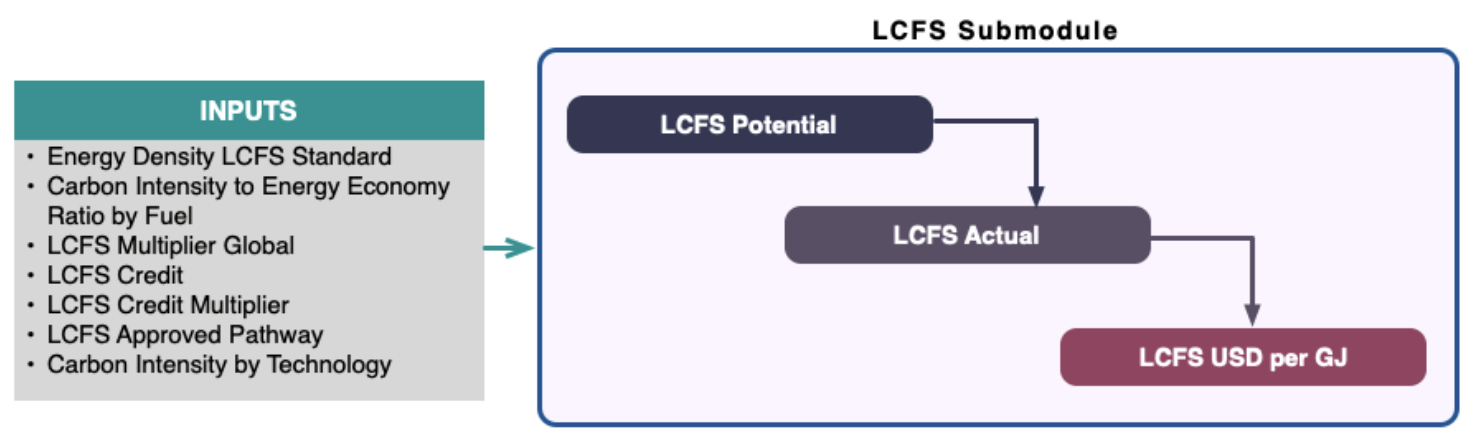

Figure 10. Generic structure for Low Carbon Fuel Standard (LCFS) calculations

The LCFS Submodule uses several inputs (left) to evaluate the potential for each pathway to obtain LCFS credits, calculate the actual LCFS credits that could be obtained, and convert the value to cost per gigajoule (USD/GJ). 


\subsubsection{Landfill-Specific Logic}

To estimate how material in landfills degrades over time and to track landfill closures, WESyS includes additional functionality in the landfill modules. To estimate the available biogas resource at a landfill, the model considers each landfill as a large digester in which organic materials, through natural processes, decompose to produce methane. The model represents the material balance associated with deposition and decomposition of mixed organic and inorganic materials (Figure 11). Though the landfill material balance is modeled as a continuous process, closures of landfills are represented as discrete events. The LF Biogas Submodule also accounts for declining gas production from closed landfills.
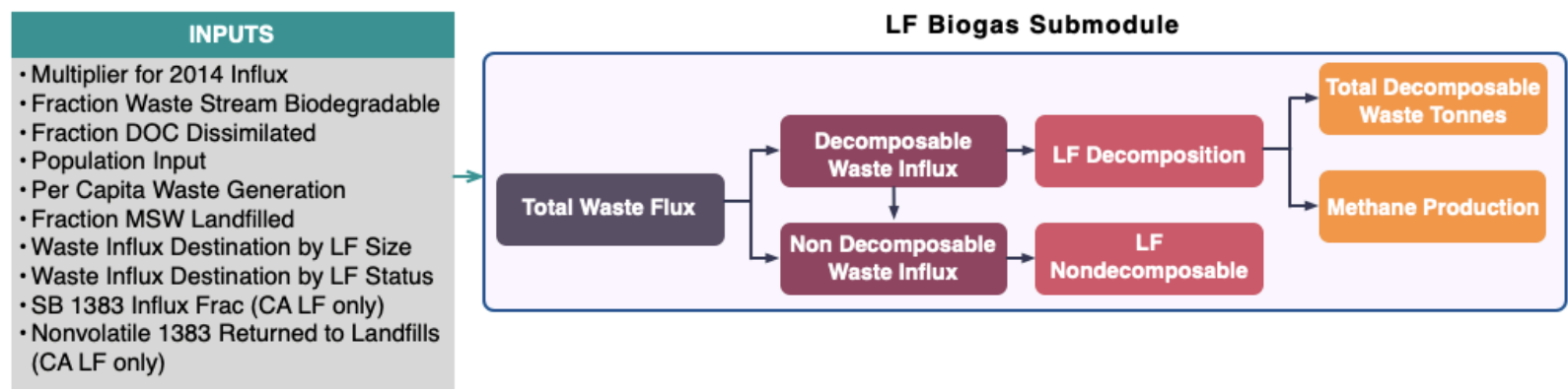

Figure 11. Generic structure for estimating methane production from landfills

The LF Biogas Submodule takes in several inputs (left) to calculate the mass of decomposable waste and the potential methane production at a landfill. These calculations include evaluations of the influx of decomposable and non-decomposable waste as well as estimations of the amount of decomposition that occurs over time based on the size and status of each landfill. MSW = municipal solid waste.

\subsubsection{Resource Initializations}

WESyS relies on site-specific resource assessment data derived from published research (Skaggs et al. 2018; T. E. Seiple et al. 2020; T. Seiple and Milbrandt 2020) to initialize resource quantities for sewage sludge and manure in the POTW and CAFO modules respectively. We aggregated these data into the size classes and regions tracked in WESyS (Table 5 for POTWs; Table 6 for dairy CAFOs). WESyS only currently accounts for CAFO waste from dairy farms; however, the model could also accommodate waste from swine and beef farms, but enabling this capability would require updating the input data.

Table 5. Summary of Initialization Data for POTWs in California (CA) and the Rest of the United States (ROTUS)

\begin{tabular}{|c|c|r|r|r|}
\hline & \multicolumn{2}{|c|}{ Mean Influx (MGD) } & \multicolumn{2}{c|}{ Number of Facilities } \\
Size Class & \multicolumn{1}{c|}{ CA } & \multicolumn{1}{c|}{ ROTUS } & \multicolumn{1}{c|}{ CA } & ROTUS \\
\hline $0-1$ & 0.3 & 0.2 & 269 & 11,000 \\
\hline $1-10$ & 3.7 & 2.9 & 170 & 3,000 \\
\hline $10-100$ & 25.8 & 26.0 & 53 & 487 \\
\hline$>100$ & 212.6 & 215.0 & 7 & 33 \\
\hline
\end{tabular}

MGD = million gallons per day

Data were derived from T. Seiple and Milbrandt (2020). 
Table 6. Summary of Initialization Data for the Number of Facilities and Average Amount of Waste in the CAFO Resource Modules ${ }^{a}$ by Region ${ }^{b}$

\begin{tabular}{|c|c|c|c|c|c|}
\hline \multirow[t]{2}{*}{$\begin{array}{l}\text { WESyS Size } \\
\text { Class }\end{array}$} & \multirow{2}{*}{$\begin{array}{l}\text { Corresponding } \\
\text { Range for } \\
\text { Number of } \\
\text { Head }\end{array}$} & \multicolumn{2}{|c|}{ Number of Dairies $^{c}$} & \multicolumn{2}{|c|}{$\begin{array}{l}\text { Average Quantity of Annual } \\
\text { Solids Collected from Each } \\
\text { Dairyc }^{c} \text { (tonne per yr) }\end{array}$} \\
\hline & & CA & ROTUS & CA & ROTUS \\
\hline Small & 500-999 & 390 & 690 & 1,975 & 1,943 \\
\hline Medium & $1,000-1,999$ & 320 & 732 & 3,761 & 3,848 \\
\hline Large & $>2,000$ & 187 & 660 & 9,026 & 10,365 \\
\hline
\end{tabular}

a CA CAFO and ROTUS CAFO

${ }^{\mathrm{b}}$ Data were derived from T. Seiple and Milbrandt (2020).

${ }^{\mathrm{c}}$ These data are only for dairies and exclude facilities that have fewer than 500 head. There are many more dairies in the United States than are listed here. However, most dairies do not have more than 500 head, which we deem to be the lowest number of head that would be cost-effective for installing stand-alone WTE technology (without aggregating from multiple facilities, which WESyS does not currently accommodate).

For the LF modules, WESyS relies on data from the U.S. Environmental Protection Agency's Landfill Methane Outreach Program (LMOP). ${ }^{12}$ For WESyS, we categorize landfill data using size categories definitions from the U.S Environmental Protection Agency (EPA 2000), which defines large landfills as having an approximate landfill design capacity of more than 2.8 million tons or 88 million $\mathrm{ft}^{3}$. All other landfills are classified as small landfills; this is an approximation for an uncontrolled non-methane organic compounds emission rate of at least 55 million tons per year. Based on our analysis of the 2016 LMOP data (EPA 2016), small landfills have an average capacity of about 2.6 million tons and large landfills have an average capacity of about 8.9 million tons.

We further categorized landfills in WESyS according to their project status as either active (i.e., landfills that are still accepting new municipal solid waste [MSW]) or inactive (i.e., landfills that have closed and are no longer accepting MSW). Active and inactive landfills both produce biogas, but at different rates. Movement from active to inactive in WESyS is based on closure rates that are projected using LMOP data on landfill capacities and MSW acceptance rates. Table 7 summarizes the number of landfills that fall into each size and project status category.

Table 7. Summary of Initialization Data used for the Number of Facilities in Each Landfill in the LF Modules (CA LF and ROTUS LF)

\begin{tabular}{|l|l|l|r|r|r|r|}
\hline \multirow{2}{*}{$\begin{array}{l}\text { Size } \\
\text { Category }\end{array}$} & \multirow{2}{*}{$\begin{array}{l}\text { Corresponding } \\
\text { Design Capacity }\end{array}$} & \multirow{2}{*}{$\begin{array}{l}\text { Project } \\
\text { Status }\end{array}$} & & \multicolumn{2}{|c|}{ Number of Landfills } & \multicolumn{2}{|l|}{$\begin{array}{l}\text { Average Initial Loading of } \\
\text { Each Landfill (tonnes) }\end{array}$} \\
\cline { 4 - 8 } & & CA & \multicolumn{1}{|l|}{ ROTUS } & CA & \multicolumn{1}{l|}{ ROTUS } \\
\hline Small & $\begin{array}{l}\text { Less than 2.5 million } \\
\text { tonnes and 2.5 million } \\
\text { cubic meters }\end{array}$ & Active & 39 & 245 & $1,215,003$ & 969,413 \\
\cline { 4 - 8 } & Inactive & 120 & 592 & 774,658 & $1,054,871$ \\
\hline
\end{tabular}

12 "Landfill Methane Outreach Program (LMOP)," U.S. Environmental Protection Agency, last updated August 6 , 2020, https://www.epa.gov/lmop. 


\begin{tabular}{|l|l|l|r|r|r|r|}
\hline \multirow{2}{*}{$\begin{array}{l}\text { Size } \\
\text { Category }\end{array}$} & \multirow{2}{*}{$\begin{array}{l}\text { Corresponding } \\
\text { Design Capacity }\end{array}$} & \multirow{2}{*}{$\begin{array}{l}\text { Project } \\
\text { Status }\end{array}$} & \multicolumn{2}{|l|}{ Number of Landfills } & \multicolumn{2}{|l|}{$\begin{array}{l}\text { Average Initial Loading of } \\
\text { Each Landfill (tonnes) }\end{array}$} \\
\cline { 4 - 8 } & & & CA & \multicolumn{1}{|l|}{ ROTUS } & CA & ROTUS \\
\hline Large & $\begin{array}{l}\text { Greater than } 2.5 \\
\text { million tonnes and } 2.5 \\
\text { million cubic meters }\end{array}$ & Active & 75 & 1,180 & $16,483,196$ & $10,223,739$ \\
\cline { 4 - 8 } & Inactive & 54 & 296 & $21,994,643$ & $6,568,069$ \\
\hline
\end{tabular}

Data were derived from LMOP (EPA 2016).

In addition, we categorize each landfill's WTE status (with or without WTE projects) in WESyS based broadly on LMOP data. The initial waste to energy distribution for the LF modules is based on the operational and candidate landfills in the LMOP data. Operational landfills already have WTE technology installed and operating. Candidate landfills for WTE projects are landfills that are (1) accepting MSW or have been closed for five years or less, (2) have at least one million tons of MSW, and (3) do not have a planned, operational, or under-construction WTE project. Candidate landfills are further subdivided into landfills with or without installed gas collection equipment for flaring biogas.

All other landfills (e.g., those that have been closed for more than five years) are categorized as potential candidate landfills. WESyS allows landfills to transition from a potential candidate landfill to a candidate landfill and from a candidate landfill to a landfill with a WTE project. Movement between landfill status categories (e.g., potential to candidate) is defined by the user and can be varied. The data for the disaggregation by project type and landfill type (e.g., candidate versus potential versus operational) are not shown here but are available within the model itself.

In addition to initializing the resources in WESyS using previously published data as described above, we also use published data to identify facilities that already have WTE production onsite, and we categorize these facilities by their current WESyS WTE technology configurations to initialize technology adoption (data not shown). Data sources for this process include LMOP (EPA 2016) for landfills and the DOE's Combined Heat and Power Installation Database (DOE 2002) for all resource types.

The resource initializations are typically treated as static quantities over the course of a simulation run (i.e., no new facilities are built, and the model only represents technology adoption across existing facilities). The LF modules are the exception, as landfills are allowed to close over time (see Section 3.1.3). In addition, for all resource modules, WESyS can run scenarios that represent changes in the total number of facilities that adopt WTE technologies, the size of the operations, and the distribution of types of technologies adopted.

\subsection{Global Modules}

The Global Inputs Module and the Global Outputs Module manage input and output data, and they perform operations that require inputs for multiple modules (e.g., modeling industrial learning for immature technologies and calculating total energy potential across multiple modules). 


\subsubsection{Global Inputs}

The Global Inputs Module performs a variety of functions, including tracking input data common to multiple resource modules and calculating per-unit revenue for incentives (Figure 12). The Global Inputs Module also contains logic for industrial learning in the Learning Submodule.

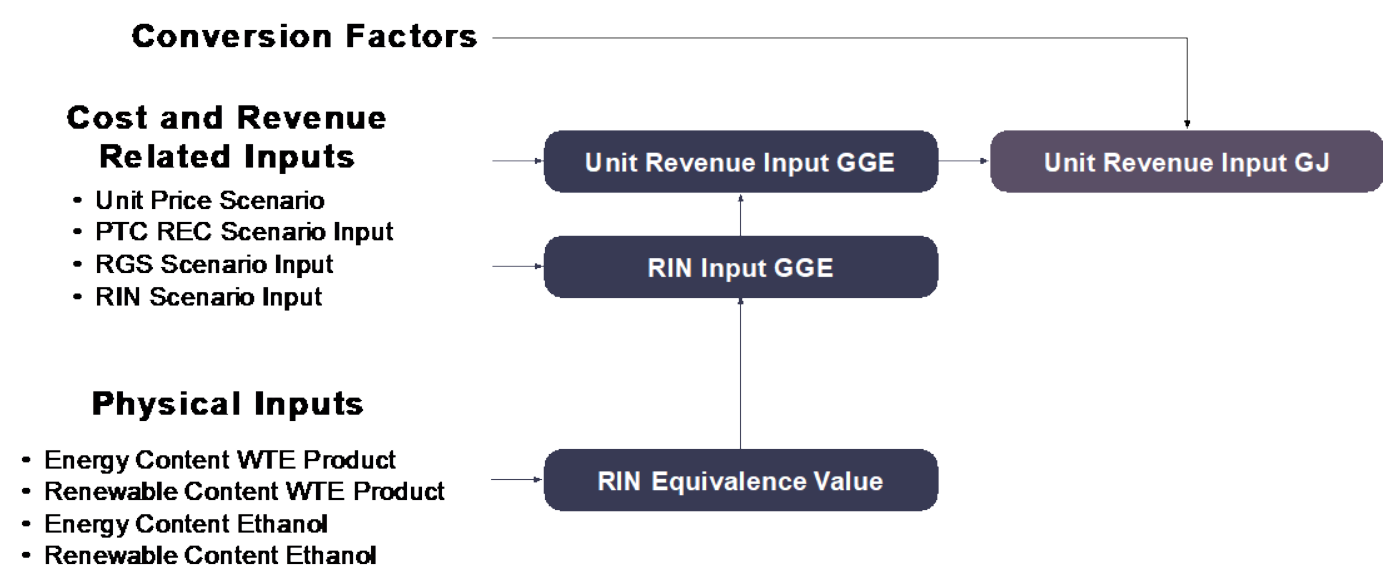

Figure 12. Diagram of per-unit revenue calculations in Global Inputs Module

The Global Inputs Module includes several calculations to convert unit revenue into a cost per gigajoule value. These calculations include computing the equivalence value for any RINs for which the WTE technology might qualify, estimating the RIN input per gallon of gasoline gallon equivalent, and then adding that to the unit revenue (on a dollar per gasoline gallon equivalent [GGE] basis) for other types of revenue sources (e.g., PTC REC and RGS).

\subsubsection{Learning Submodule}

WESyS includes a Learning Submodule that simulates the learning process for immature technologies (Figure 13). It tracks the rate of growth of experience with a technology configuration and uses this information to monitor the number of doublings of experience. WESyS then uses the rate of doublings to update the indices of maturity for each immature technology and then calculate the maturity gap between the current level of technology maturity and full maturity.

\section{Learning Submodule}

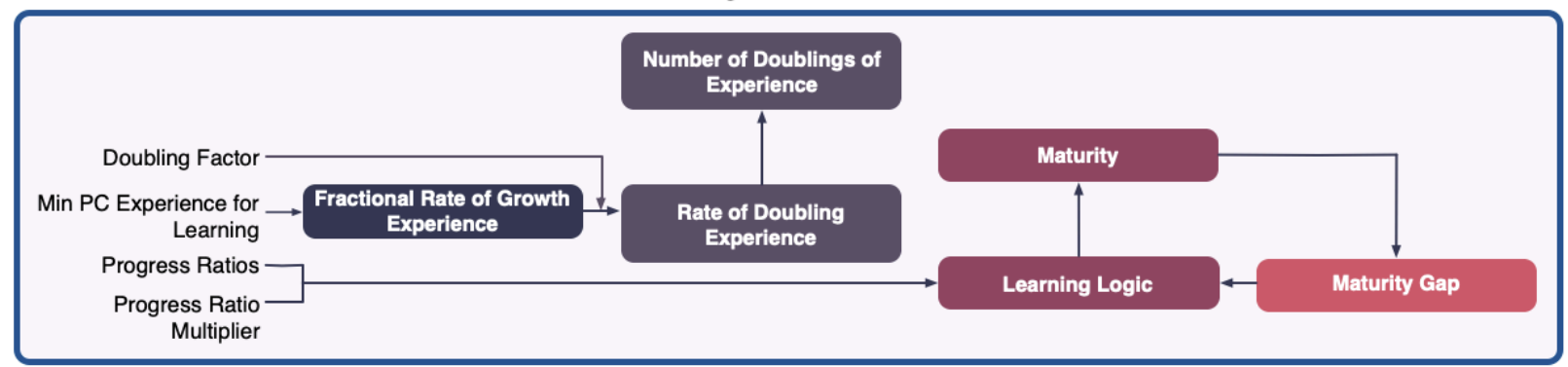

Figure 13. Tracking of doubling of experience for learning

The Learning Submodule uses several inputs (left) to estimate the maturity of technologies that are still being developed (i.e., HTL). The submodule tracks the fractional growth rate in experience and computes the rate of doublings of experience. It then combines these values with progress ratios and learning logic to compute the maturity of the technology and assess the maturity gap. PC = precommercial. 
The Learning Submodule uses an industrial learning curve concept for immature WTE technologies. Equation 2 illustrates a single-factor learning curve, and Equation 3 shows the progress ratio (PR), which represents the cost after each cumulative doubling in industrial output. Smaller PRs result in faster industrial learning:

$$
\mathrm{Y}=\mathrm{aX}
$$

where:

$\mathrm{Y}$ is the current unit cost.

$\mathrm{X}$ is the cumulative production.

$a$ is the unit cost of the initial unit.

$\mathrm{b}$ is the slope of the function when plotted on a log-log scale.

$$
\mathrm{PR}=2^{-\mathrm{b}}
$$

The model includes two levels of maturity: precommercial (PC) and commercial. The learning process occurs on at both levels of maturity (the same learning logic for technology doubling is used for both stages of maturity), and the learning from precommercial maturity cascades into commercial maturity as the technology evolves (Figure 14).

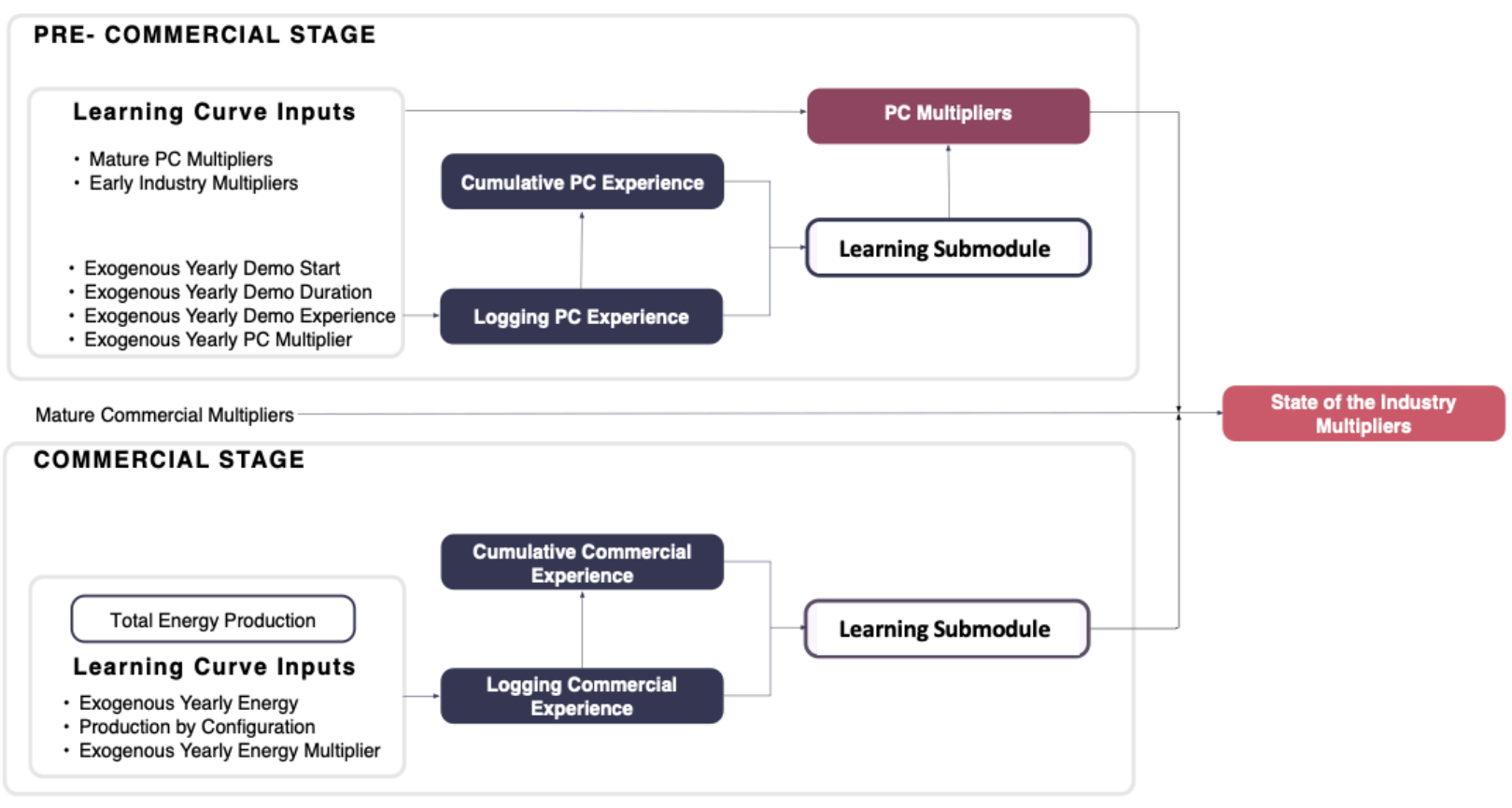

Figure 14. Stages of industrial learning

WESyS includes two stages of industrial learning: precommercial (PC) and commercial. The cumulative experience for each of these types of development are input to a learning submodule, which estimates the change in maturity, which is then used to update the State of the Industry multipliers, which modify six attributes of the technology configuration (Figure 15). 
The level of maturity informs the techno-economic multipliers for immature technologies, which modify six attributes of the technology configuration (Figure 15, page 23):

1. Process yield

2. Operating cost growth (i.e., how much more costly an early plant might be before the technology is mature)

3. Input capacity (i.e., bottlenecks relative to the capacity of mature plants)

4. Capital cost growth

5. Investor risk premium (i.e., how much higher the hurdle rate would than for a mature technology)

6. Access to debt financing (i.e., how much can be financed via borrowing).

It is important to note again here that WESyS currently models only one immature technology: HTL. The default data for variables related to learning in WESyS are listed in Table 8. WESyS users could adjust these default learning data within the current model structure (for HTL), modify the existing structure to add a new immature technology pathway(s), or both, depending on the desired application.

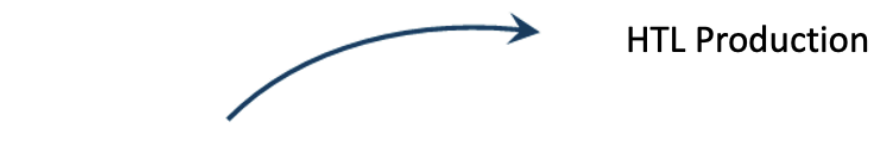

Investment in HTL Facilities
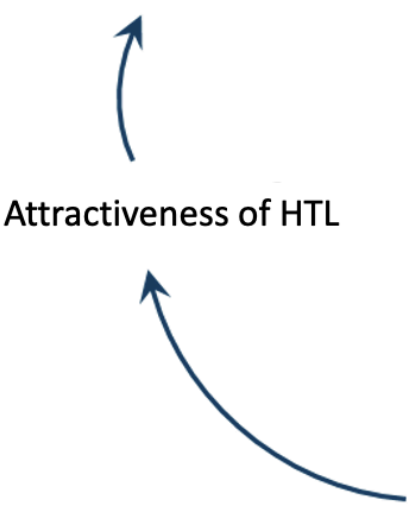

Techno-Economic Multipliers

- Process yield

- Operating cost growth

- Input capacity

- Capital cost growth

- Investor risk premium

- Access to debt financing

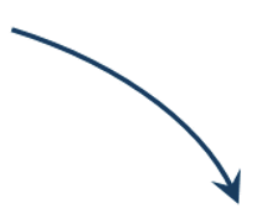

HTL Maturity

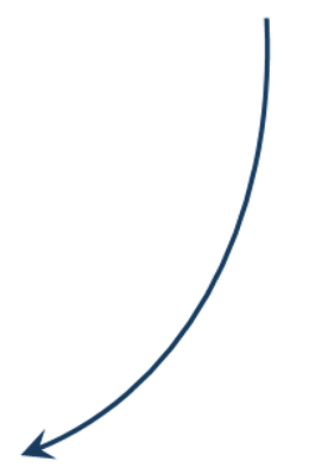

Figure 15. Influence diagram for learning

The Learning Submodule in WESyS includes a reinforcing feedback loop. It tracks investment in HTL facilities and computes the quantity of HTL production, which informs the maturity of HTL. The maturity of the technology, in turn, influences the techno-economic multipliers, which modify the financial attractiveness of HTL and thereby inform investment in HTL facilities. 
Table 8. Default Data for Learning Variables

\begin{tabular}{lll}
\hline Model Factor & Default Data & Units \\
\hline Exogenous Yearly Demo Start & 2018 & year \\
Exogenous Yearly Demo Duration & 4 & years \\
Exogenous Demo Experience & 3,942 : HTL; all else: 0 & hours/year \\
Exogenous Yearly Precommercial Multiplier & HTL: 1; all else: 0 & unitless \\
Mature Precommercial Multipliers & $0.5-2.5$ & unitless \\
Early Industry Multipliers & $0-2$ & unitless \\
Exogenous Yearly Energy Multiplier & HTL: 1; all else: 0 & unitless \\
Min Precommercial Experience for Learning & 1,000 & hours \\
Commercial Progress Ratios & HTL: 0.7; all else: 0 & XYZ/doubling \\
Precommercial Progress Ratios & HTL: 0.8; all else: 0 & XYZ/doubling \\
Progress Ratio Multiplier & HTL: 1; all else: 0 & unitless \\
\hline
\end{tabular}

Sources: Snowden-Swan et al. 2017; Peterson et al. 2015

\subsubsection{Global Outputs}

The Global Outputs Module collects data from all the resource modules and aggregates the outputs to estimate total energy production by resource, WTE technology configuration, and region (Figure 16).

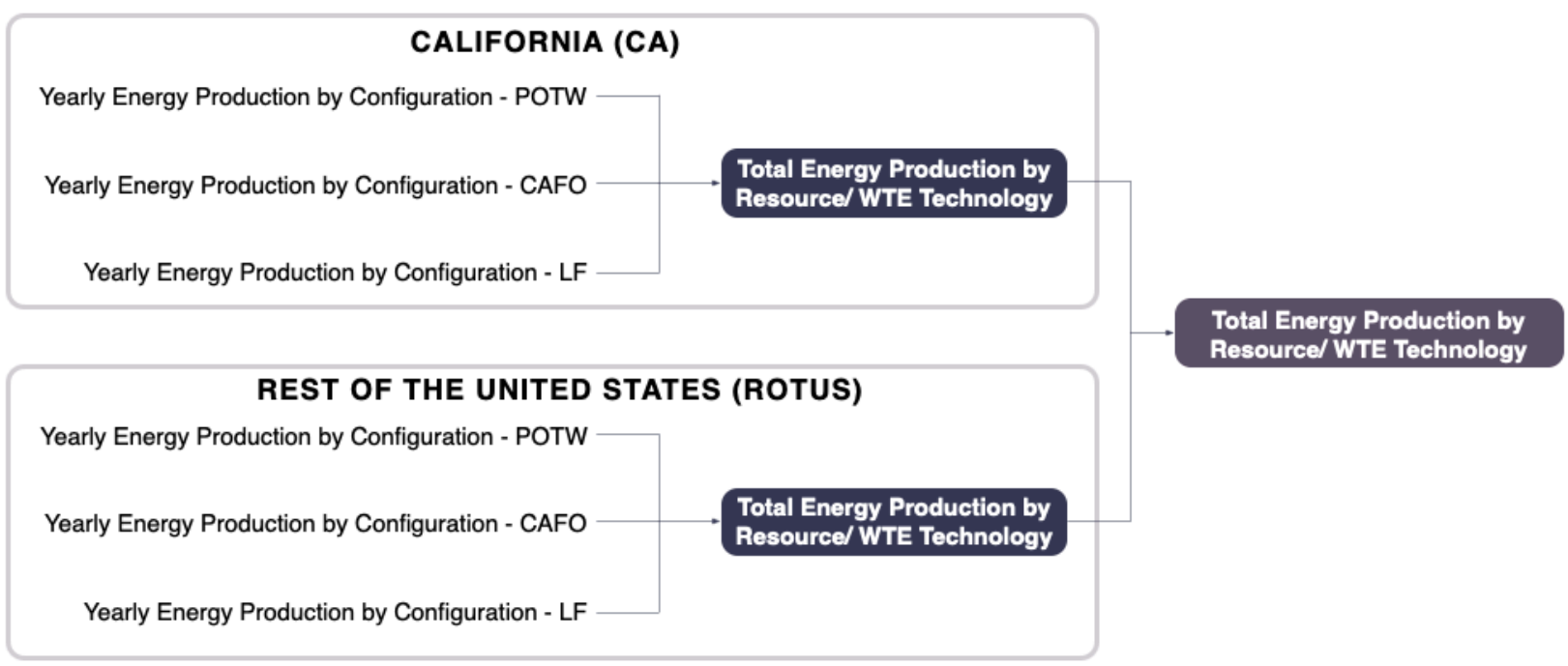

Figure 16. Structure of global output

The Global Outputs Module of WESyS tracks total energy production by resource type and WTE technology within each region and aggregates these values to compute total energy production in the United States. 
In addition, WESyS calculates the total number of installations and the total potential energy production that could be achieved for each technology configuration (Figure 17).

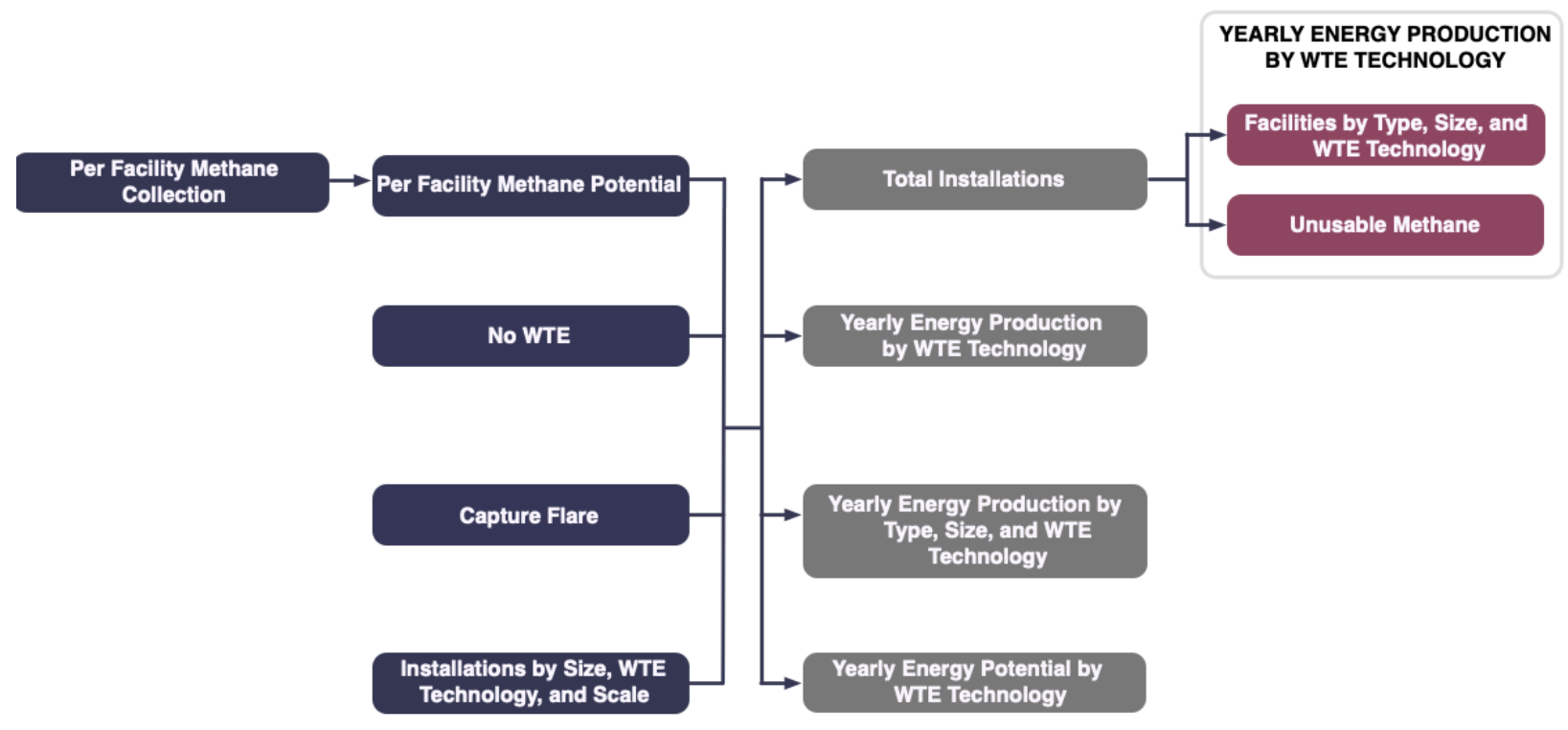

Figure 17. Resource module output for California landfills

Additional metrics (e.g., useable methane and facilities by type, size, and WTE technology) are also tracked within each resource module and are reported to the Global Outputs Module. 


\section{Sample Outputs}

WESyS tracks investment and build-out of the WTE industry over time. And WESyS results are reported as a snapshot of either the industry at a point in time (e.g., total number of facilities that have invested in a given technology pathway or total energy production from a given pathway) or the development trajectory over time (e.g., the number of facilities investing per year).

Figure 18 illustrates a range of output trajectories from WESyS for a series of input scenarios. Every run is shown individually with the densest areas having the most runs (you can see the outliers on the edge of ROTUS). The figure illustrates the growth in energy production over time for each run, and it highlights both the difference in energy potential between the ROTUS and CA regions and the amount of variation in outputs over all the runs. We observe an asymptotic trend because the model is limited by the number of POTWs, as it does not allow for build-out of new POTW facilities. WESyS can also report results by facility type and resource type (Figures 19 and 20). Note that these figures are intended for illustrative purposes only (to demonstrate what the model can do); they are not intended for obtaining absolute magnitudes.

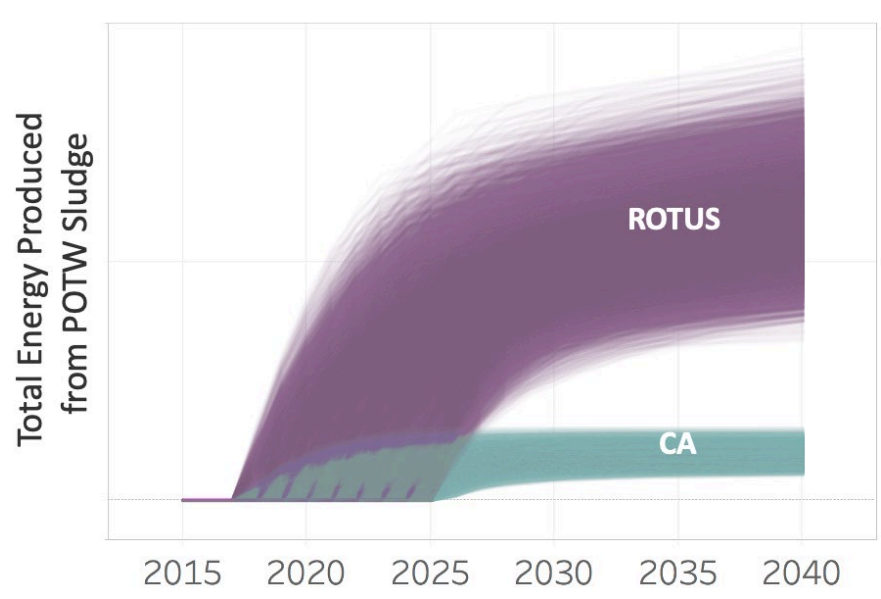

Figure 18. Sample energy production trajectories from the CA and ROTUS POTW modules

Energy production results for a series of input scenarios (every run is shown individually with the densest areas having the most runs; note the outliers on the edge of the ROTUS profile). These results are intended to illustrate the type of output WESyS can generate; values may vary based on input data. 


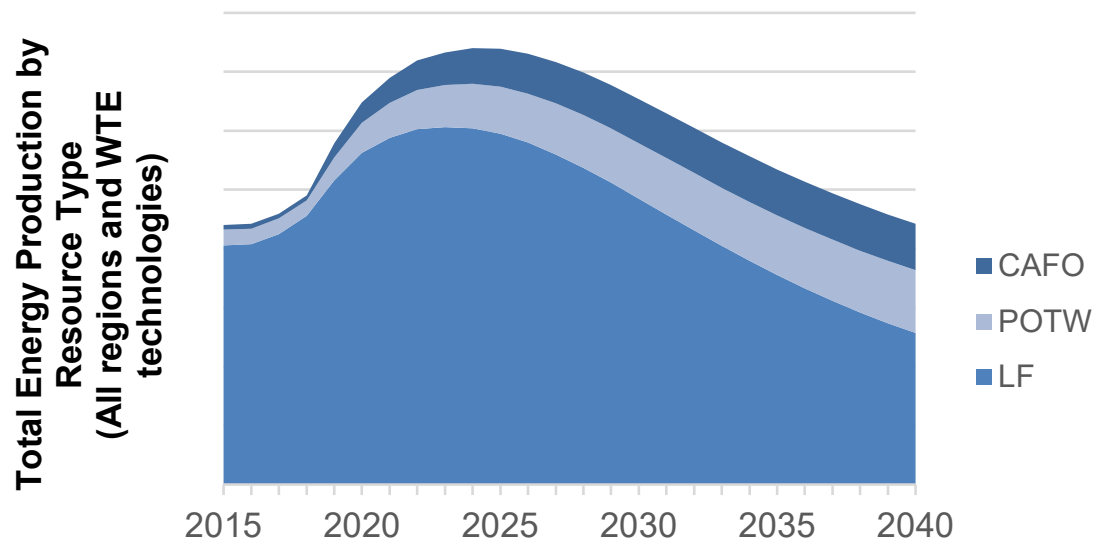

Figure 19. Sample time series WESyS output for total energy production by resource type

The figure is an example of a breakdown of a single WESyS trajectory (all regions and all WTE technologies) by resource type. These results are intended to illustrate the type of output WESyS can generate; values may vary based on input data.

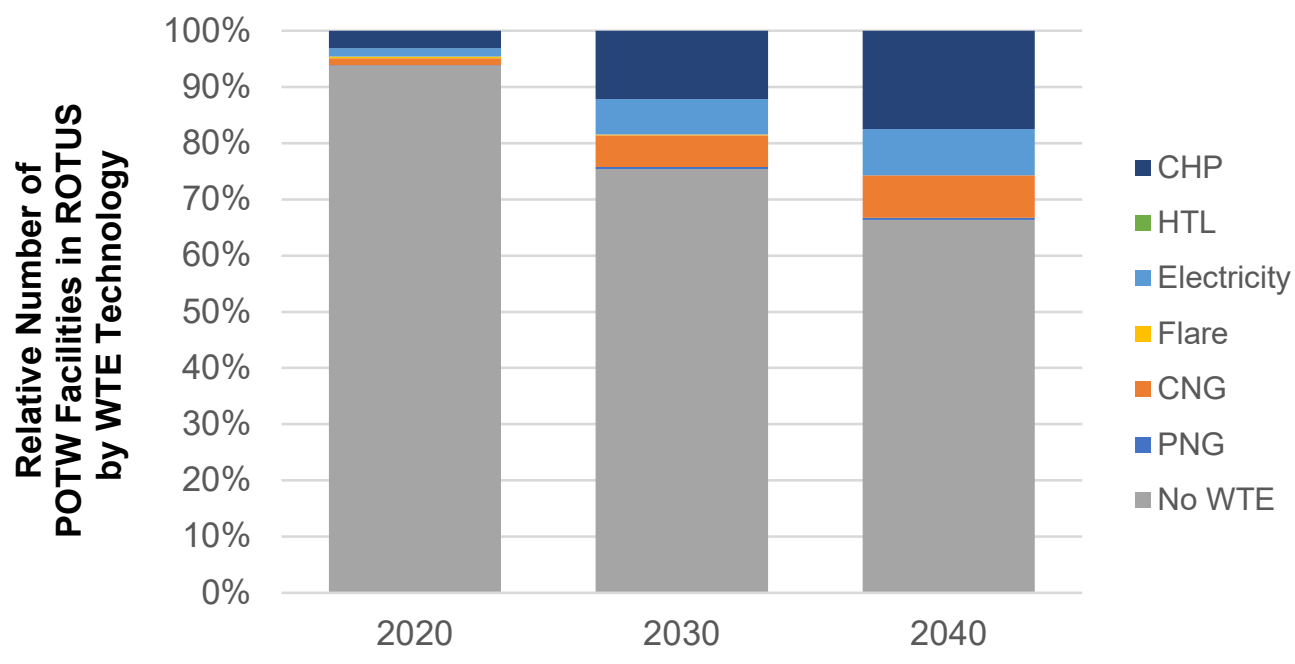

Figure 20. Sample breakdown of WESyS ROTUS POTW facility counts by WTE technology

The figure is an example of a breakdown of the relative number of ROTUS POTW facilities by WTE technology for a single WESyS run at three points in time. These results are intended to illustrate the type of output WESyS can generate; values may vary based on input data. 


\section{Conclusion}

The Waste-to-Energy System Simulation (WESyS) model is a system dynamics model that simulates the build-out of the U.S. WTE industry over time for wet and gaseous waste resources from three types of facilities: landfills, concentrated animal feeding operations, and publicly owned treatment works. The model is designed, and has been used, to guide national-level decision-making about WTE technological configurations. Stakeholders from industry, government, and academia have reviewed WESyS and provided useful input on modeling approach and scope. Overall, these reviewers have recognized that WESyS is most relevant for national- or regional-scale users focused on broad questions of market growth, resource utilization, and technological learning. Though WESyS is unsuitable for individual facility-level decision-making and adoption decisions because it does not include enough site-specific detail, the model can be used to explore how future scenarios might influence WTE adoption and to understand how industry evolution might influence technology cost and energy potential.

Potential users of WESyS include national government agencies, industry trade groups, utilities, state-level decision makers (including industry and government), and water resource organizations. The model can help analysts and decision makers develop quantitative scenarios about future industry development, guide expectations about WTE potential, provide state-ofindustry background information, assess the potential impact of new WTE technologies, inform planning processes, and identify how incentives, techno-economics, and market conditions might influence the deployment of WTE.

Future model development efforts could explore:

- Increasing regionality: The current two-region representation is insufficient for certain key decision-making processes that require greater regional specificity.

- Expanding technology representation to improve realism of choice modeling (e.g., by including enhanced anaerobic digestion options)

- Increasing the representation of investment decisions: Although WESyS models financing and development lag times, facility investment decisions often consider additional factors, including technology and incentive risk, waste variability, resiliency, payback, facilityspecific planning and implementation challenges.

- Incorporating greater granularity to better differentiate incentives by waste type, particularly for the California LCFS and RINs.

This report describes the current implementation of WESyS. Future versions of the model may incorporate additional capabilities or modify calculations within the code. Refer to the GitHub repository at https://github.com/NREL/WESyS-Model for the latest version of the model and supporting user documentation. 


\section{References}

California State Legislature. 2016. Senate Bill No. 1383: Chapter 395: SB-1383 Short-Lived Climate Pollutants: Methane Emissions: Dairy and Livestock: Organic Waste: Landfills. https://leginfo.legislature.ca.gov/faces/billTextClient.xhtml?bill_id=201520160SB1383.

CARB. 2020. "Low Carbon Fuel Standard." California Air Resources Board. 2020. https://ww2.arb.ca.gov/our-work/programs/low-carbon-fuel-standard.

CPUC. 2018. "Actions to Limit Utility Costs and Rates: Public Utilities Code Section 913.1 Annual Report to the Governor and Legislature." California Public Utilities Commission. https://www.cpuc.ca.gov/WorkArea/DownloadAsset.aspx?id=6442457283.

DOE. 2002a. "U.S. DOE Combined Heat and Power Installation Database." 2002. https://doe.icfwebservices.com/chpdb/.

- 2017. "Biofuels and Bioproducts from Wet and Gaseous Waste Streams: Challenges and Opportunities." DOE/EE-1472. U.S. Department of Energy Office of Energy Efficiency and Renewable Energy Bioenergy Technologies Office. https://doi.org/10.2172/1342171. - n.d. "Waste to Energy." DOE Office of Energy Efficiency \& Renewable Energy. Accessed August 11, 2020b. https://www.energy.gov/eere/bioenergy/waste-energy. EIA. 2018. “Annual Energy Outlook 2018." U.S. Energy Information Administration. 2018. https://www.eia.gov/outlooks/archive/aeo18/.

EPA. 2000. "Standards of Performance for New Stationary Sources and Guidelines for Control of Existing Sources: Municipal Solid Waste Landfills." Federal Register. April 10, 2000. https://www.federalregister.gov/documents/2000/04/10/00-8151/standards-ofperformance-for-new-stationary-sources-and-guidelines-for-control-of-existing-sources. . 2015. "Overview for Renewable Fuel Standard." Overviews and Factsheets. U.S. Environmental Protection Agency Renewable Fuel Standard Program. August 4, 2015. https://www.epa.gov/renewable-fuel-standard-program/overview-renewable-fuelstandard. . 2016. "Landfill Gas Energy Project Data and Landfill Technical Data." Overviews and Factsheets. U.S. Environmental Protection Agency Office of Air and Radiation. April 20, 2016. https://www.epa.gov/lmop/landfill-gas-energy-project-data-and-landfill-technicaldata.

Humphreys, Kenneth King. 1991. Jelen's Cost and Optimization Engineering. McGraw-Hill Science, Engineering \& Mathematics.

Lilien, Gary L., Philip Kotler, and K. Sridhar Moorthy. 1992. Marketing Models. Prentice-Hall. Murray, Brian C., Christopher S. Galik, and Tibor Vegh. 2017. "Biogas in the United States: Estimating Future Production and Learning from International Experiences." Mitigation and Adaptation Strategies for Global Change 22 (3): 485-501. https://doi.org/10.1007/s11027-015-9683-7.

Oregon Department of Environmental Quality. 2015. "State of Oregon: Oregon Clean Fuels Program - Oregon Clean Fuels Program Overview." 2015. https://www.oregon.gov/deq/ghgp/cfp/Pages/CFP-Overview.aspx.

Peterson, Steve, Corey Peck, Dana Stright, Emily Newes, Danny Inman, Laura Pellegrini, and David Hsu. 2015. "An Overview of the Biomass Scenario Model.” NREL/CP-6A2060172. Golden, CO (United States): National Renewable Energy Laboratory. https://www.nrel.gov/docs/fy15osti/60172.pdf. 
Roos, KF, JB Martin, and MA Moser. 2004. "A Manual for Developing Biogas Systems at Commercial Farms in the United States-AgSTAR Handbook." EPA-430-B-97-015. U.S. Environmental Protection Agency.

Seiple, Timothy E., Richard L. Skaggs, Lauren Fillmore, and André M. Coleman. 2020. "Municipal Wastewater Sludge as a Renewable, Cost-Effective Feedstock for Transportation Biofuels Using Hydrothermal Liquefaction.” Journal of Environmental Management 270 (September): 110852. https://doi.org/10.1016/j.jenvman.2020.110852.

Seiple, Timothy, and Anelia Milbrandt. 2020. "National Wet Waste Inventory (NWWI)" 1 (October). https://doi.org/10.17632/f4dxm3mb94.1.

Skaggs, Richard L., André M. Coleman, Timothy E. Seiple, and Anelia R. Milbrandt. 2018. "Waste-to-Energy Biofuel Production Potential for Selected Feedstocks in the Conterminous United States." Renewable and Sustainable Energy Reviews 82 (3): 2640 51. https://doi.org/10.1016/j.rser.2017.09.107.

Snowden-Swan, Lesley J, Yunhua Zhu, Mark D Bearden, Timothy E Seiple, Susanne B Jones, Andrew J Schmidt, Justin M Billing, et al. 2017. "Conceptual Biorefinery Design and Research Targeted for 2022: Hydrothermal Liquefaction Processing of Wet Waste to Fuels.” Richland, WA (United States): Pacific Northwest National Laboratory (PNNL). https://doi.org/10.2172/1415710.

Sterman, John. 2000. Business Dynamics: Systems Thinking and Modeling for a Complex World. Irwin/McGraw-Hill.

Walker, Brian, and David Salt. 2012. Resilience Thinking: Sustaining Ecosystems and People in a Changing World. Island Press. 


\section{Appendix. Default Cost Data}

Tables A-1 through A-4 provide the default fixed capital investment (FCI) and operating cost (Op Cost) data that are used in WESyS.

These data were derived from Murray, Galik, and Vegh (2017) and Snowden-Swan et al. (2017).

Table A-1. Default Fixed Capital Investment Costs for Facilities without any Capture and Flare Technology (in 2014 USD)

\begin{tabular}{|l|l|r|r|r|r|r|r|}
\cline { 2 - 7 } \multicolumn{1}{c|}{} & Size of Facility & CF & Elec. & CNG & PNG & CHP & HTL \\
\hline \multirow{4}{*}{ POTW } & 0-1 MGD & 594,715 & 972,475 & $1,061,974$ & $1,183,558$ & $1,414,874$ & 972,475 \\
\cline { 2 - 8 } & $1-10$ MGD & $1,293,327$ & $1,776,200$ & $1,886,261$ & $2,035,777$ & $5,191,957$ & $1,776,200$ \\
\cline { 2 - 8 } & $10-100$ MGD & $6,607,981$ & $8,463,214$ & $8,590,267$ & $8,704,615$ & $16,161,781$ & $8,463,214$ \\
\cline { 2 - 8 } & $>100$ MGD & $36,473,062$ & $45,846,762$ & $46,212,759$ & $46,359,158$ & $57,198,711$ & $45,846,762$ \\
\hline \multirow{3}{*}{ LF } & Small & $1,200,000$ & $4,200,000$ & $4,430,000$ & $4,650,000$ & $4,200,000$ & n/a \\
\cline { 2 - 8 } & Large & $3,300,000$ & $8,500,000$ & $8,730,000$ & $8,950,000$ & $8,500,000$ & n/a \\
\hline \multirow{3}{*}{ CAFO } & Small & 2,599 & 730,000 & 860,000 & 860,000 & $7,367,285$ & 730,000 \\
\cline { 2 - 8 } & Medium & 3,894 & $1,100,000$ & $1,230,000$ & $1,230,000$ & $10,238,221$ & $1,100,000$ \\
\cline { 2 - 8 } & Large & 6,924 & $2,600,000$ & $2,800,000$ & $2,800,000$ & $17,314,190$ & $2,600,000$ \\
\hline
\end{tabular}


Table A-2. Default Fixed Capital Investment Costs for Facilities with Capture and Flare Technology Already Installed (in 2014 USD)

\begin{tabular}{|l|l|r|r|r|r|r|r|}
\cline { 2 - 8 } \multicolumn{1}{c|}{} & Size of Facility & CF & Elec & CNG & PNG & CHP & HTL \\
\hline \multirow{4}{*}{ POTW } & $0-1$ MGD & 0 & 594,216 & 683,714 & 805,298 & $1,380,159$ & 594,216 \\
\cline { 2 - 8 } & $1-10$ MGD & 0 & 779,421 & 889,482 & $1,038,998$ & $5,098,631$ & 779,421 \\
\cline { 2 - 8 } & $10-100$ MGD & 0 & $2,555,233$ & $2,682,286$ & $2,796,634$ & $15,982,781$ & $2,555,233$ \\
\cline { 2 - 8 } & $>100$ MGD & 0 & $10,873,700$ & $11,239,697$ & $11,386,096$ & $56,893,026$ & $10,873,700$ \\
\hline \multirow{3}{*}{ LF } & Small & 0 & $3,000,000$ & $3,230,000$ & $3,450,000$ & $3,000,000$ & n/a \\
\cline { 2 - 8 } & Large & 0 & $5,200,000$ & $5,430,000$ & $5,650,000$ & $5,200,000$ & n/a \\
\hline \multirow{3}{*}{ CAFO } & Small & 0 & 727,401 & 857,401 & 857,401 & $7,367,285$ & 727,401 \\
\cline { 2 - 8 } & Medium & 0 & $1,096,106$ & $1,226,106$ & 926,106 & $10,238,221$ & $1,096,106$ \\
\cline { 2 - 8 } & Large & 0 & $2,593,076$ & $2,793,076$ & $2,793,076$ & $17,314,190$ & $2,593,076$ \\
\hline
\end{tabular}


Table A-3. Default Operating Costs (Op Cost) for Facilities without any Capture and Flare Technology (in 2014 USD per year)

\begin{tabular}{|l|l|c|c|c|c|c|c|}
\cline { 2 - 8 } \multicolumn{1}{c|}{} & Size of Facility & CF & Elec & CNG & PNG & CHP & HTL \\
\hline \multirow{4}{*}{ POTW } & $0-1 \mathrm{MGD}$ & 13,000 & 32,849 & 37,771 & 44,062 & 32,849 & 20,436 \\
\cline { 2 - 8 } & $1-10 \mathrm{MGD}$ & 36,700 & 66,748 & 73,695 & 97,564 & 66,748 & 178,413 \\
\cline { 2 - 8 } & $10-100 \mathrm{MGD}$ & 65,724 & 150,328 & 158,027 & 325,251 & 150,328 & $1,184,014$ \\
\cline { 2 - 8 } & $>100 \mathrm{MGD}$ & 340,160 & $1,403,838$ & $1,541,178$ & $2,718,874$ & $1,403,838$ & $9,731,624$ \\
\hline \multirow{3}{*}{ LF } & Small & 55,000 & 185,000 & 231,000 & 231,000 & 185,000 & n/a \\
\cline { 2 - 8 } & Large & 160,000 & 690,000 & 880,000 & 880,000 & 690,000 & n/a \\
\hline \multirow{3}{*}{ CAFO } & Small & 76,000 & 99,000 & 108,500 & 124,321 & 99,000 & 319,684 \\
\cline { 2 - 8 } & Medium & 116,000 & 151,000 & 160,500 & 191,261 & 151,000 & 553,243 \\
\cline { 2 - 8 } & Large & 260,000 & 339,000 & 355,000 & 442,241 & 339,000 & $1,328,042$ \\
\hline
\end{tabular}


Table A-4. Default Operating Costs (Op Cost) for Facilities with Capture and Flare Technology Already Installed (in 2014 USD per year)

\begin{tabular}{|l|l|r|r|r|r|r|r|}
\cline { 2 - 8 } \multicolumn{1}{c|}{} & Size of Facility & CF & Elec & CNG & PNG & CHP & HTL \\
\hline \multirow{4}{*}{ POTW } & $0-1 \mathrm{MGD}$ & 0 & 19,849 & 24,771 & 31,062 & 19,849 & 18,799 \\
\cline { 2 - 8 } & $1-10 \mathrm{MGD}$ & 0 & 30,048 & 36,995 & 60,864 & 30,048 & 174,011 \\
\cline { 2 - 8 } & $10-100 \mathrm{MGD}$ & 0 & 84,604 & 92,303 & 259,527 & 84,604 & $1,175,571$ \\
\cline { 2 - 8 } & $>100 \mathrm{MGD}$ & 0 & $1,063,678$ & $1,201,018$ & $2,378,714$ & $1,063,678$ & $9,713,642$ \\
\hline \multirow{3}{*}{ LF } & Small & 55,000 & 130,000 & 176,000 & 176,000 & 130,000 & n/a \\
\cline { 2 - 8 } & Large & 160,000 & 530,000 & 720,000 & 720,000 & 530,000 & n/a \\
\hline \multirow{3}{*}{ CAFO } & Small & 0 & 23,000 & 32,500 & 48,321 & 23,000 & 319,684 \\
\cline { 2 - 8 } & Medium & 0 & 35,000 & 44,500 & 75,261 & 35,000 & 553,243 \\
\cline { 2 - 8 } & Large & 0 & 79,000 & 95,000 & 182,241 & 79,000 & $1,328,042$ \\
\hline
\end{tabular}

